\title{
Automatic Lighting Controls Demonstration: Long-term Results
}

\author{
F. Rubinstein \\ Energy and Environment Division \\ Lawrence Berkeley Laboratory \\ University of California \\ Berkeley, California 94720
}

July 1991

Reprinted from PG\&E Customer Systems Report 008.1-91.21

with the permission of Pacific Gas and Electric, 1992

This work was supported in part by the Customer Systems Area of the Department of Research and Development at Pacific Gas and Elestric Company and in part by the Assistant Secretary for Conservation and Renewable Energy, Office of Building Technologies, Building Equipment Division of the U.S. Department of Energy under Contract No. DE-AC03-76SF00098. 
Report Issued:

October 18, 1991

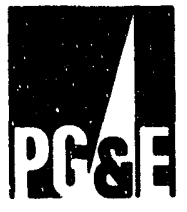

\section{Research and \\ Development}

Automatic Lighting Controls

Demonstration: Long-term Results

Customer Systems

Report 008.1-91.21

Project Manager: Matt W. Andersen

Commerclal End Use

Final Report, July 1991

Prepared by:

Francis Rubinsteln

Lighting Systems Research

Lawrence Berkeley Laboratory

Building 90, Room 3111

Berkeley, California 94720

Prepared for:

Pacific Gas and Electric Company

Department of Research and Development 3400 Crow Canyon Road

San Ramon, Callifornia 94583

오 1991 by PG\&E 


\section{LEGAL. NOTICE}

Pacific Gas and Electric Company (PG\&E) makes no warra. 'y or representation, expressed or implied, with respect to the accuracy, completeness, or usefulness of the information contained in this report, or that the use of any information, apparatus, method, or process disclosed in this report may not infringe upon privately owned rights. Nor does PG\&E assume any liability with respect to use of, or damages resulting from the use of, any information, apparatus, method, or process disclosed in this report.

ㄷ) 1991 by PG\&E

All Rights Reserved 


\section{ACKNOWLEDGMENTS}

This study was supported by the Customer Systems Area of the Department of Research and Development at Pacific Gas and Electric Company and partially by the assistant secretary for Conservation and Renewable Energy, Office of Building Technologies, Building Equipment Division of the U.S. Department of Energy, under contract No. DE-AC08-76SF00098.

The author would like to thank all the individuals who helped make this project a success. Special thanks are due to Robert Slaney (Goldsmith and Lathrop) who helped coordinate the installation, and Joseph Condon (Goldsmith and Lathrop) who, with his staff, installed the system at the demonstration site. 


\section{EXECUTIVE SUMMARY}

An advanced electronically ballasted lighting control system was installed in a portion of an office building to measure the energy and demand savings.

The lighting control system used an integrated lighting control scenario that included daylight following, lumen depreciation correction, and scheduling. The system reduced lighting energy on weekdays by $62 \%$ and $51 \%$ in the north and south daylit zones, respectively, compared to a reference zone that did not have controls. During the summer, over $75 \%$ energy savings were achieved on weekdays in the north daylit zone. Even in the south interior zone, which benefitted little from daylight, correction strategies (scheduling and lumen depreciation) and adjustment of the aisleway lights to a low level resulted in energy use of only half that of the reference zone. Although, in general, the savings varied over the year due to changing daylight conditions, the energy reduction achieved with controls could be fit using a simple analytical model (Figure ES-1).

Significant savings also occurred during core operating hours (6 A.M. to 6 P.M.) when it is more expensive to supply and use energy. Compared to the usage in the reference zone, energy reductions of $49 \%, 44 \%$, and $62 \%$ were measured in the south daylit, south interior, and north daylit zones, respectively, during core operating hours throughout the year.

Lighting energy usage on weekends decreased dramatically in the zones with controls, with the usage in the north daylit zone only $10 \%$ that of the reference zone.

A simple survey developed to assess occupant response to the lighting control system showed that the occupants were satisfied with the light levels provided.

During the load-shedding test, the lighting control system was used to lower light levels by about $15 \%$ for short intervals in the afternoons in simulated response to a peak demand situation. The dimming controls were effective in implementing load-shedding control; occupant response to the strategy was neutral.

A novel two-part control photosensor was effective in providing appropriate control; it allowed daylighting and lumen maintenance strategies to be implemented simultaneously with the same hardware. With this photocontrol system, design light levels were maintained at the workplane regardless of the daylight contribution or the age of the lighting system.

$00819121 / 918443 /$ ppu276 


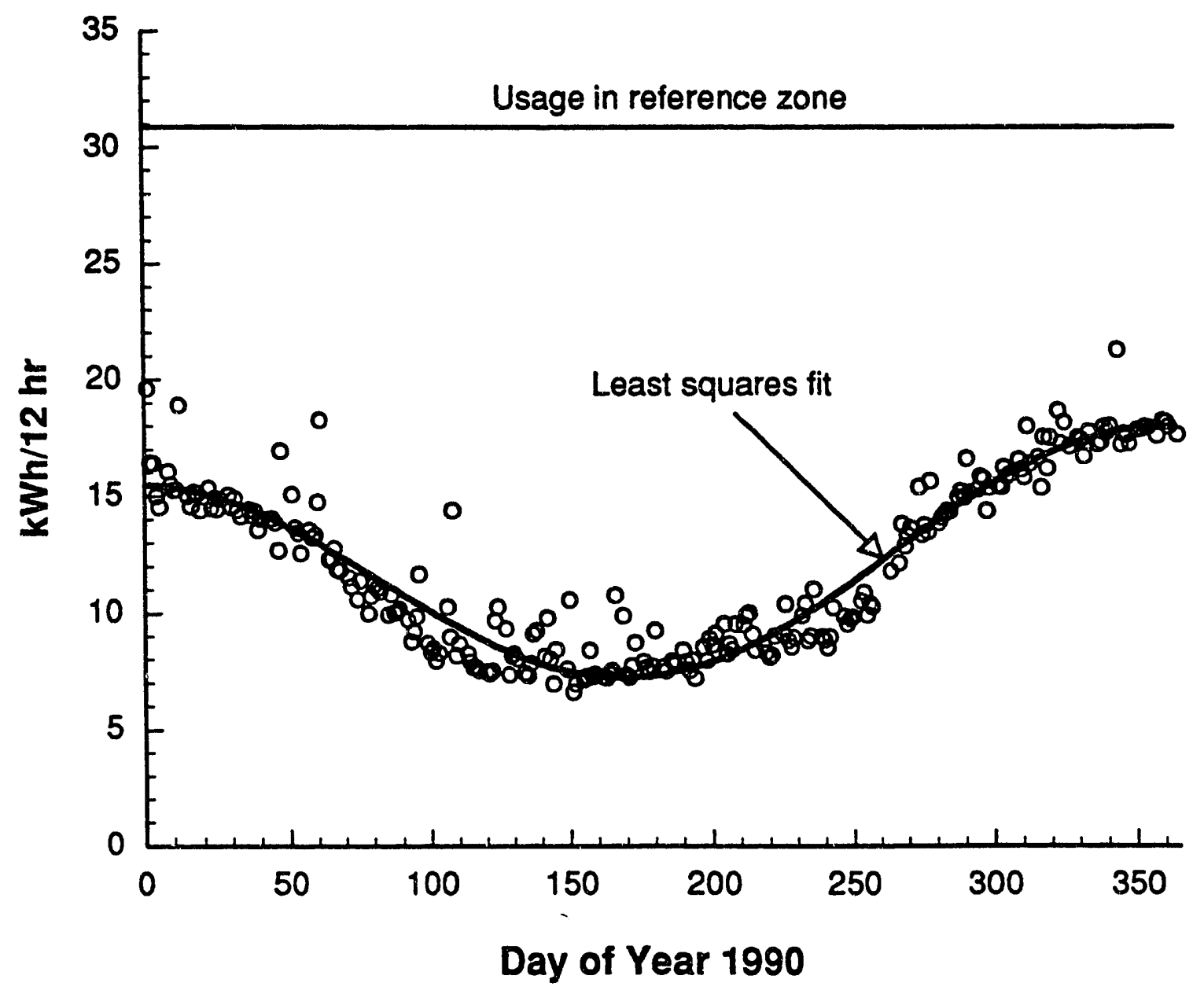

Figure ES-1. Daily energy use computed for core hours only (6 A.M. to 6 P.M.) on weekdays for north daylit zone compared to core hours usage in reference zone. Least squares fit to the north zone data is of the form $y=10.83+0.0067$ (day) $+4.73 \cos \left((\right.$ day +9$\left.) / 365^{*} 2 * \pi\right)$, which fits the data significantly with a correlation coefficient $R^{2}=0.91$. 

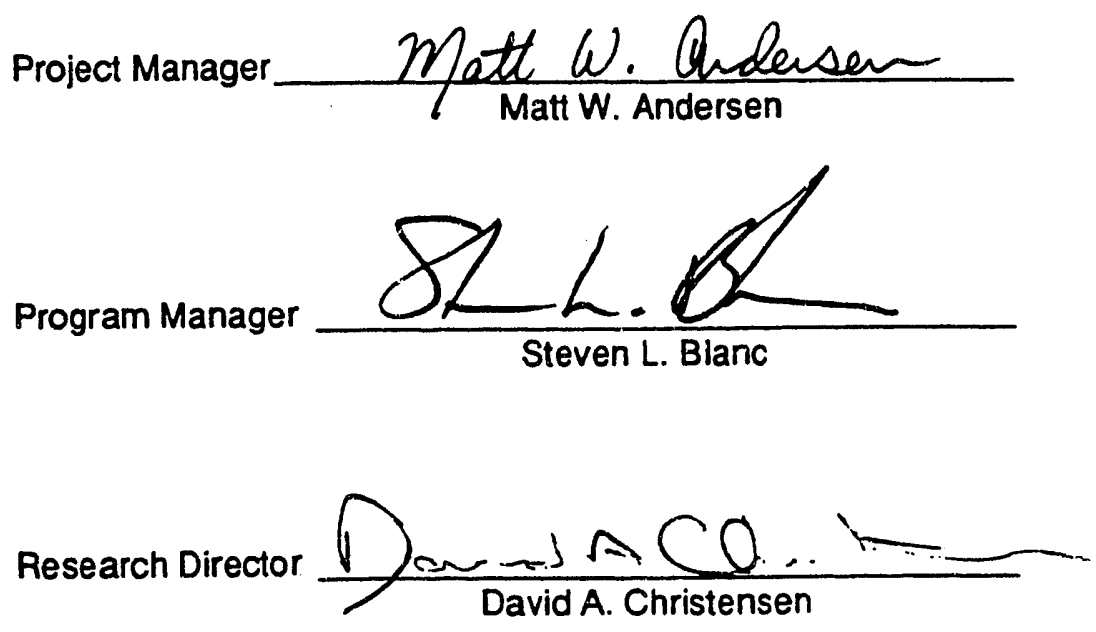

$00819121 / 918443 /$ ppu276

iv 


\section{CONTENTS}

1 INTRODUCTION ............................................................................................. 1-1

2 METHODS .........................................................................................................

SUMMARY OF PHASE 1 WORK (1989) ....................................................................

BUILDING DESCRIPTION ...................................................................................

EXISTING LIGHTING SYSTEM .............................................................................

DEMONSTRATION SYSTEM ................................................................................

LAYOUT OF CONTROL GROUPS .......................................................................

INSTRUMENTATION ......................................................................................... 2

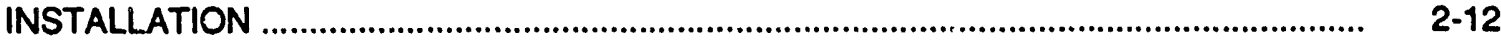

3 RESULTS ..........................................................................................................

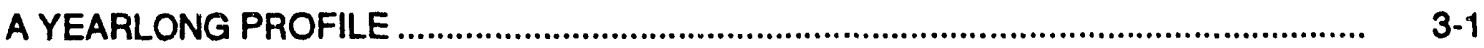

TYPICAL DAY LIGHTING POWER USAGE …………………..................................

EFFECT OF DRAPES ON ENERGY SAVINGS .........................................................

ENERGY SAVINGS WITH DAYLIGHTING ALONE .....................................................

ADDED EFFECT OF TUNING ……………………………...............................

LOAD-SHEDDING TESTS ................................................................................

LIGHT LEVEL MEASUREMENTS ........................................................................

TEMPERATURE MEASUREMENTS .......................................................................

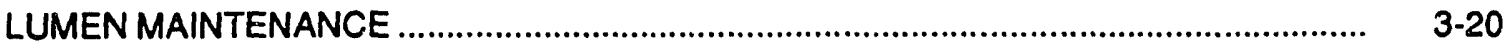

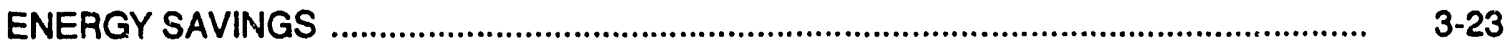

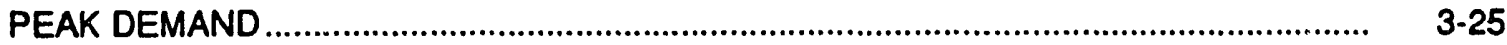

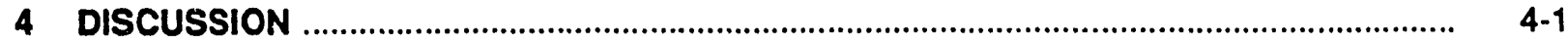

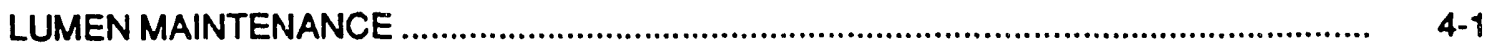

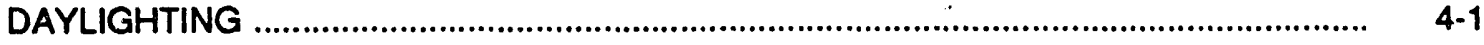

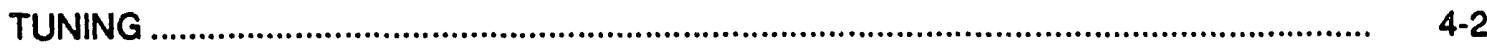

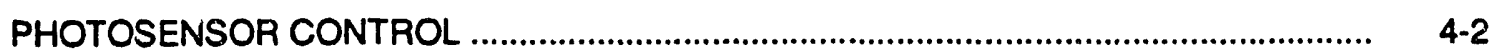

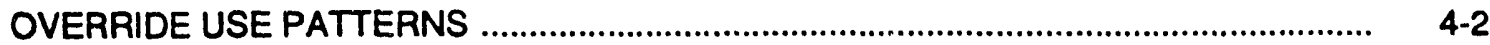

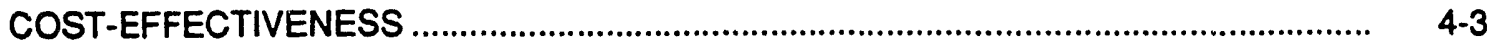

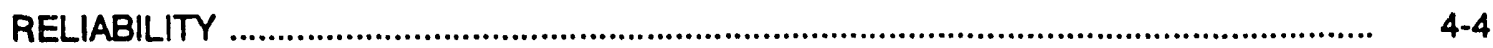

5 CONCLUSIONS AND RECOMMENDATIONS …………............................................ 5

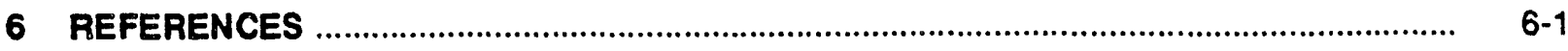

Appendix A:

GLOSSARY 


\section{FIGURES}

Figure $\quad$ Page

2-1 Lighting control system schematic ..................................................................................... $2-4$

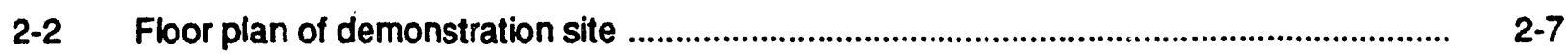

2-3 Location of control photosensor relative to fixture ........................................................

3-1 Plot of daily energy use on weekdays for north daylit zone ............................................

3-2 Plot of daily energy use on weekdays for south daylit zone ............................................. 3-3

3-3 Plot of daily energy use on weekdays for south interior zone .......................................... 3-4

3-4 Plot of daily energy use on weekends ........................................................................ 3-6

3-5 Lighting power in all zones for typical weekday near the winter solstice.......................... 3-7

3-6 Lighting power in all zones for typical weekday near the spring equinox ....................... 3-8

3-7 Lighting power in all zones for typical weekday near the summer solstice ...................... $3-9$

3-8 Effects of drapes on lighting power in the south daylit zone for a typical clear day ......... $3-11$

3-9 Effect of load shedding on lighting power in all zones for a typical day ..........................

3-10 Workplane illuminance at varying distances from north window for typical weekday during load-shedding test ...........................................................................

3-11 Workplane illuminance at varying distances from north window for typical weekday near the winter solstice ................................................................................. $\quad 3-16$

3-12 Workplane illuminance at varying distances from north window for typical 3-17

3-13 Workplane illuminance at varying distances from north window for typical weekday near the summer solstice

3-14 Workplane illuminance at varying distances from south window for typical weekday near the winter solstice

3-15 Lamp wall, fixture compartment, and plenum temperatures in the fixture instrumented with thermocouples

3-16 Workplane illuminance due to electric light only at 4.5 and $8.5 \mathrm{ft}$ from the north window for selected days in 1990

3-17 Maximum weekday lighting demand (May 1 to October 31,1990 ) .................................. 3-26 


\section{TABLES}

Table

Page

3-1 Average 1990 Weekday Lighting Energy Use...

3-24

3-2 Average 1990 Weekend Lighting Energy Use 
Section 1

\section{INTRODUCTION}

Lighting consumes a significant proportion of electric energy use in commercial buildings. Averaged over all commercial building stock, lighting is responsible for $37 \%$ of the building sector's electrical energy consumption. Twenty-five percent of all the energy consumed in commercial buildings is used directly for the provision of lighting (DOE 1989). It is no surprise, therefore, that the lighting industry has devoted much effort to improving the efficiency of light sources and fixtures. Much less work has been devoted to improving the way lighting energy use is managed in buildings. The all-too-common sight of lights burning in unoccupied office buildings long into the night is mute testimony to the enormous extent of lighting waste. Thus, it is worthwhile inquiring whether the energy and demand savings obtained from better control of lighting might result in an equal energy saving as improvements to hardware efficiency at an equal or lower cost. This report presents the results of a demonstration of an advanced lighting control system that provides appropriate light levels for the performance of visual tasks while reducing lighting energy consumption and peak demand.

There are four basic strategies to reduce energy consumption for lighting with lighting controls: scheduling, lumen maintenance, daylighting, and tuning (see glossary in Appendix A for detailed definitions). A fifth strategy, load shedding, moderates lighting power at times of peak demand primarily to reduce demand charges. These strategies have been identified in previous research, and the energy savings attributable to certain strategies, particularly daylighting and scheduling, have been measured in a limited number of building sites (Jaekel and Rea 1983; Levy 1980; Rubinstein and Karayel 1984). Despite this body of research, well-documented studies of the persistent energy savings from systems exploiting all these techniques have not been reported. Thus, demonstration of the long-term energy savings from a system using all control strategies combined was a major objective of this project.

A second objective of this work was to demonstrate a photocell control scheme that effectively permits the optimal integration of daylighting and lumen maintenance strategies with the same hardware. A third objective was to assess the response of the building occupants to determine if these types of systems will be accepted.

In Section 2, we briefly describe the demonstration site, the installed control equipment, the monitoring instrumentation, and the simultaneous implementation of all four lighting control strategies at the site. Section 3 presents the results obtained at the demonstration site in 1990. Results are presented in terms of both the energy saved per day and the lighting power reductions accomplished during core operating 
hours (6 A.M. to 6 P.M.). The long-term measured energy savings with daylighting and lumen maintenance are presented. Details of the measured results and their significance are explained in Section 4, and conclusions and recommendations are presented in Section 5. 


\section{Section 2}

\section{METHODS}

\section{SUMMARY OF PHASE 1 WORK (1989)}

In 1989, under contract to PG\&E's Department of Research and Development, Lawrence Berkeley Laboratory (LBL) managed and designed the installation of an advanced electronically ballasted lighting control system at the Watergate Tower 1 in Emeryville: California. The purpose of the Phase 1 work was to measure the energy and peak demand reduction capability of an electronically ballasted fluorescent lighting control system under actual building conditions. An experimental protocol was developed to allow the savings potential of various lighting control strategies to be analyzed separately, where possible, and in appropriate combinations. To separate the effect of simply replacing the standard ballasts with more efficient electronic ballasts from the impact of the improved lighting control, we measured the power input to the four lighting circuits serving the demonstration site and light levels at representative locations before installing the electronic ballasts or controls. Then, after installing the system, we repeated the measurements to assess the change in lighting system performance with respect to light output, input power, and efficacy. The experimental design called for a sequence of tests ranging in duration from three weeks to several months, during which time we measured the performance of the new system and its capabilities to exploit the various control strategies.

In October 1989, the lighting control system was calibrated to exploit all lighting control strategies, and the lighting system has been operating in this mode since that time. In the report submitted to PG\&E for the Phase 1 work, all results obtained between installation (May 1989) and the end of the Phase 1 contract (December 1989) were reported. The results from the initial tests indicated that an electronically ballasted, dimmable lighting system with the appropriate control strategies could reduce energy and lighting demand by approximately $50 \%$ (Rubinstein and Verderber 1990). However, due to the necessity of measuring the savings from strategies individually as well as various shakedown problems encountered when the system was being commissioned, the data were only collected from all zones using all control strategies during the wintertime. Since these data tend to underestimate the savings potential from controls, a follow-on contract was negotiated to permit the continued testing of the controls for a full year's duration, and this report presents the results obtained during the entire year of 1990 .

\section{BUILDING DESCRIPTION}

\section{Layout}

The demonstration site was one portion of the sixth floor of an office building located in the city of Emeryville in the San Francisco Bay Area. The entire sixth floor of this building, the Watergate Tower 1 , is leased by 
the Insurnet Company. The site area is approximately $4,544 \mathrm{ft}^{2}$, or roughly $22 \%$ of the sixth floor's gross area. The building has a relatively unobstructed view to the north and south.

The building architecture is conventional, with windows running the length of all the exterior walls. The windows are $6.5 \mathrm{ft}$ high measured from the top of the window sill ( 40 inches from the floor) to just below the level of the dropped ceiling. The windows are standard clear glass with an estimated transmittance of $88 \%$. The two window walls running along the north and south sides of the demonstrat site are equipped with loosely woven, heavy drapes that can be drawn to reduce thermal and visual discomfort when the sun is low in the sky. Based on ou. yisual observations, the occupants on the north side never close the drapes, apparently because direct sun penetrates only late in the afternoon (during the summer) when most of the occupants have left. The cocupants on the south side of the building usually close their drapes for most of the day and then open themi at dusk.

\section{Uses}

Almost all the people working on the sixth floor use computer terminals for a significant portion of their work. Because so many individuals use CRT screens, the overhead lighting system had been previously retrofitted with small-cell louvers to reduce the reflected glare off the CRTs.

Many of the individuals work standard shifts, i.e., 8 A.M. to 5 P.M. However, a few individuals work at least a few hours during the graveyard shift. Prior to the demonstration project, the lights throughout most of the site were left on at night to accommodate the needs of just a few individuals.

The office area in the south portion of the site consists of partitioned cubicles branching off a linear circulation aisle. These partitions are $6 \mathrm{ft}$ high and colored a medium light beige. Though the partitions are not dark, their height is sufficient to block much of the daylight that would otherwise penetrate deeper into the space.

In contrast to the south zone, the north zone is much more open: a few low partitions are between some desks. The north-facing zone receives little glare from the windows. As in the south zone, CRT screens are ubiquitous, and many individuals have antiglare screens installed.

\section{EXISTING LIGHTING SYSTEM}

The existing lighting system at the demonstration site consists of 4-lamp lay-in fluorescent troffers on 8-ft centers. The ceiling lighting system operates on $277 \mathrm{Vac}$. In use throughout the site were 34-W lamps and a mixture of standard and energy-efficient core-coil ballasts of various ages. 
The original lenses had been previously replaced with 1 -inch "paracube" louvers to reduce the amount of thinh angle light produced by the luminaires. While relatively inefficient for fixture efficiency, the paracube buvers greatly reduce reflections of ceiling fixtures on the computer screens.

Prior to instailation of the controls, the lighting system was controlled by rotary-type switches installed at the entrance to the office space. If the lights were not already on, individuals entering the space would rotate one switch to inticate their lighting zone and then depress an adjacent switch to activate their lights. The shape and size of these zones was dictated by the existing branch circuit wiring for the lighting system. Generally, the occupante did not use the entrance switches to any degree. This function was left to a security guard, who turned the lights off fairly regularly at 3:30 A.M. and turned them on at approximately 5:00 A.M.

\section{DEMONSTRATION SYSTEM}

A schematic of the entire system, including the associated control hardware, is shown in Figure 2-1.

\section{Three-Lamp Electronic Ballasts}

The high-frequency electronic fluorescent lamp ballasts used in this demonstration were advanced commercial prototypes manufactured by the Braydon Corporation. The ballasts convert $60 \mathrm{~Hz}$ alternating current to $65 \mathrm{kHz}$, thereby increasing lamp efficacy and virtually eliminating flicker. Each ballast operates three lamps rather than two, allowing higher system efficiency by distributing the ballast losses over a larger number of lamps.

The ballasts can be dimmed over a wide range: from $100 \%$ to approximately $20 \%$ of full power. Light output at maximum dim is approximately $15 \%$ of full light output. Dimming is achieved either by a low-voltage control signal to the ballasts or by a manual adjustment of a potentiometer mounted directly in the ballast. In an installation, each ballast is connected to a pair of wires (the control wiring), which connects all the ballasts in a given control group. All the ballasts in a control group dim in unison in proportion to the amplitude of a $5 \cdot \mathrm{kHz}$ square wave transmitted over the low-voltage control wiring.

\section{Controller}

The controller is an electronic circuit that transmits a variable voltage signal on low-voltage wires to control the light levels for all the ballasts in a particular control group. One controller is required per control group. The controller board can be used to set the illumination level manually (from a potentiometer on the board) or automatically in response to a signal from ceiling-mounted photosensors. In addition, the controller can serve as the interface between a building energy management system (EMS) and the lighting system. Thus, ime-oi-day contiol can be executed by using the EMS to provide appropriate commands as a function of 


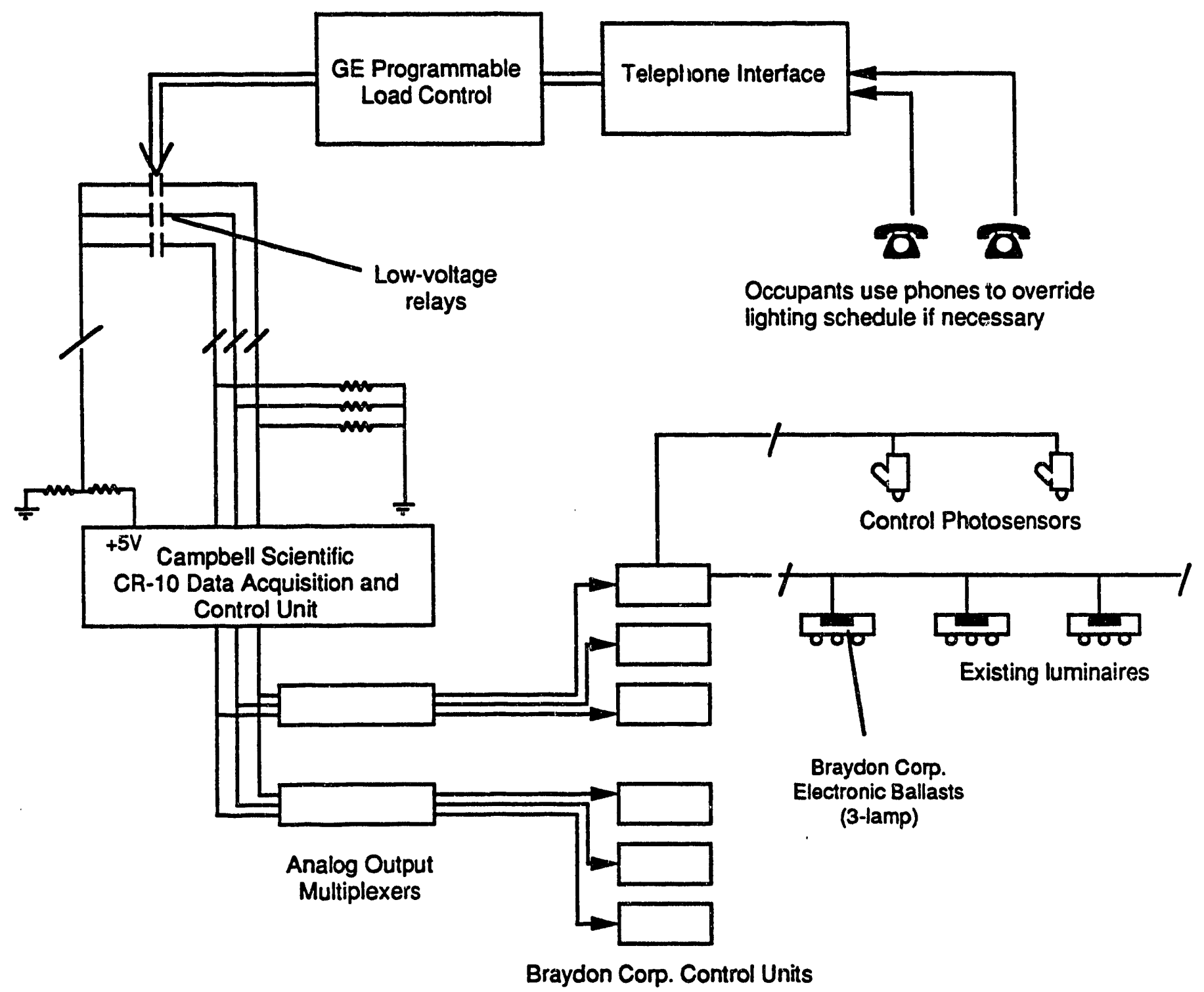

Figure 2-1. Lighting control system schematic with related equipment. 
time of day and year. When the controller is in automatic mode (i.e., photosensor control is in operation), the set point light level that the controller will maintain can be changed by the building EMS as a function of time. The controllers used in this demonstration project were manufactured by the Braydon Corporation. The controller boards were mounted in the electric room; for many installations, it would be more convenient to mount them nearer the controlled lights to facilitate system calibration.

\section{Input control from digital-to-analog converter}

The controllers are designed to accept analog inputs (via a 4-20 mA current loop) from an EMS to change the supplied illumination level at different times of the day or to respond to a demand monitor. For the purpose of this demonstration, the controllers were modified to extinguish the lamps when supplied with a 5-V signal from an EMS input. When the input voltage supplied by the EMS was zero, the controller would command the ballasts to full power. By supplying voltages between 0 and $4 \mathrm{~V}$, any intermediate light level can be achieved. (Input voltages between 4 and $5 \mathrm{~V}$ cause unpredictable results; following the manufacturer's advice, we avoided this region). Supplying a $5-V$ input caused the lamp current (and light output) to go to zero, but the baliasts a 1 consurned a small amount of power (approximately $2 \mathrm{~W} / \mathrm{ballast}$ ).

The Watergate Tower is not equipped with an EMS capable of providing the variable command voltages to the controller. Consequently, for this demonstration we used a Campbell Scientific CR-10 Data Acquisition and Control Unit with two 4-channel multiplexed digital-10-analog (D/A) converters to provide the necessary voltage supply functions. We programmed the $C R-10$ to schedule the lighting operating hours to provide reduced light levels for the cleaning crew. In addition, as described below, the CR-10 was used to process switch inputs that were activated either from a preprogrammed schedule or from an override system that the occupants could use to switch their lighting zones on and off as necessary.

\section{CR-10 used for Scheduling Control}

We programmed the CR-10 to implement a scheduling control scheme for weekday operation. This schedule drives the lights to a reduced light level ( $35 \%$ of full power) at 5 P.M. and switches them off at 2 A.M. the following morning. (This schedule was based on conversations with management to accommodate the anticipated schedule of the cleaning crew.) Thus, in the absence of any overrides, the CR-10 would switch the lights on to reduced level for 21 hours a day on weekdays. (No schedule was imposed on weekends. If occupants needed lighting on the weekends, they used the telephone override.) Then, we programmed the CR-10 to process switch inputs as described in the following subsection. 


\section{Switch Input Processing}

In this site, an existing relay-based switching system (General Electric Programmable Control system) was already in operation to control the lighting and HVAC systems in other portions of the Watergate Otfice complex. The GE system can switch latching relays on and off based on any desired switching schedule or on inputs from a telephone interface system. We used this system in conjunction with the CR-10 to automatically switch the lights on at the beginning of the work day and to process switch inputs that can be activated by the occupants using their touchtone telephones.

We assigned three relays to the system, each relay corresponding to a control zone. Low-voltage wires were run between these relays and the CR-10 in the sixth-floor electric room. The CR-10 was programmed to check the state of the relays at 5-second intervals and to command the lighting controllers to nominal full light output as long as the relay was closed. The GE system, in turn, closes or opens the relays either by means of a preprogrammed schedule or in response to the telephone interface. Building personnel programmed the switching system to close all three relays at 5 A.M. on weekdays and open them at 6 P.M. When the CR-10 detected a closed relay, it commanded the controllers to drive the lamps at nominal full power. Once an opened relay was detected, control of the light level "dropped through" to the CR-10's underlying reduced lighting schedule.

In addition to the preprogrammed schedule, the GE system can also switch a particular relay when so instructed by the telephone interface. This provided the link by which the occupants could restore their light levels to full, should they need to work after 6 P.M. Furthermore, the system was instructed to override any telephone-input overrides at 3-hour intervals. This last measure prevents occupant overrides from keeping the lights on unnecessarily if the occupants neglect to switch off the lights themselves.

\section{Photosensors}

To take advantage of available daylight and to compensate for lumen depreciation, the control system requires photosensors to measure the illumination in the space (daylight plus electric light). Novel two-part photosensors developed by the Braydon Corporation were used to compensate for lumen depreciation effects as well as to permit daylight-linked control. These photosensors were mounted in the ceiling immediately adjacent to selected fixtures in each control group (see Figure 2-2). Each photosensor consisted of two photocells (silicon photodiodes) mounted in a hollow plastic stalk (Figure 2-3). One photocell was mounted at the end of the stalk aimed downwards into the space, while the other was mounted higher up the stalk and aimed upwards (at about $45^{\circ}$ to the horizontal) at the lamps of the immediately adjacent fixture. The lower photocell, fitted with an opaque shield to prevent it from viewing out the window, is used to provide a measure of the daylight component that is approximately proportional to the daylight 


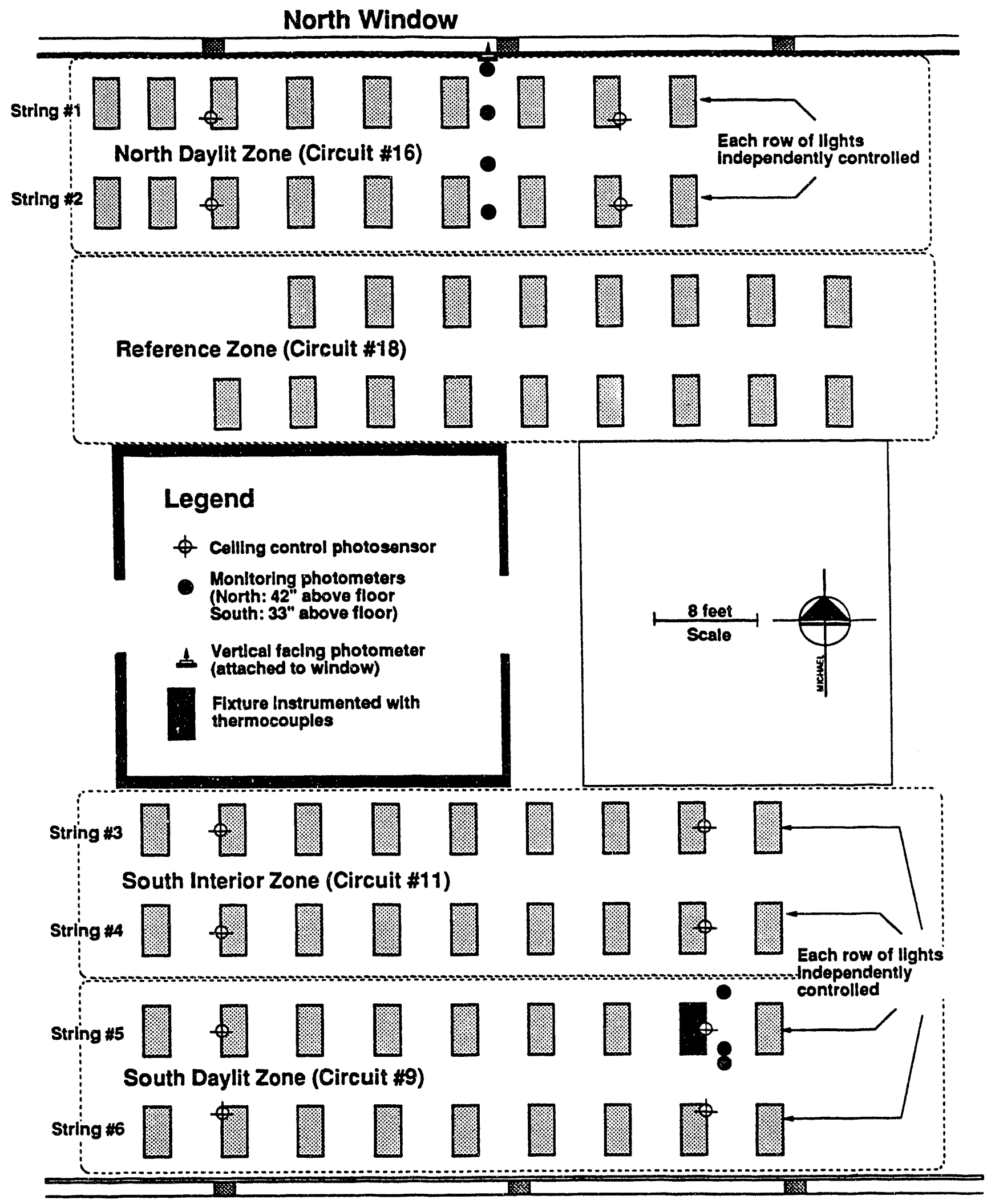

\section{South Window}

Figure 2-2. Floor plan of demonstration site showing control zones and locations of ceiling-mounted photosensors and monitoring and tempcrature instrumentation. 

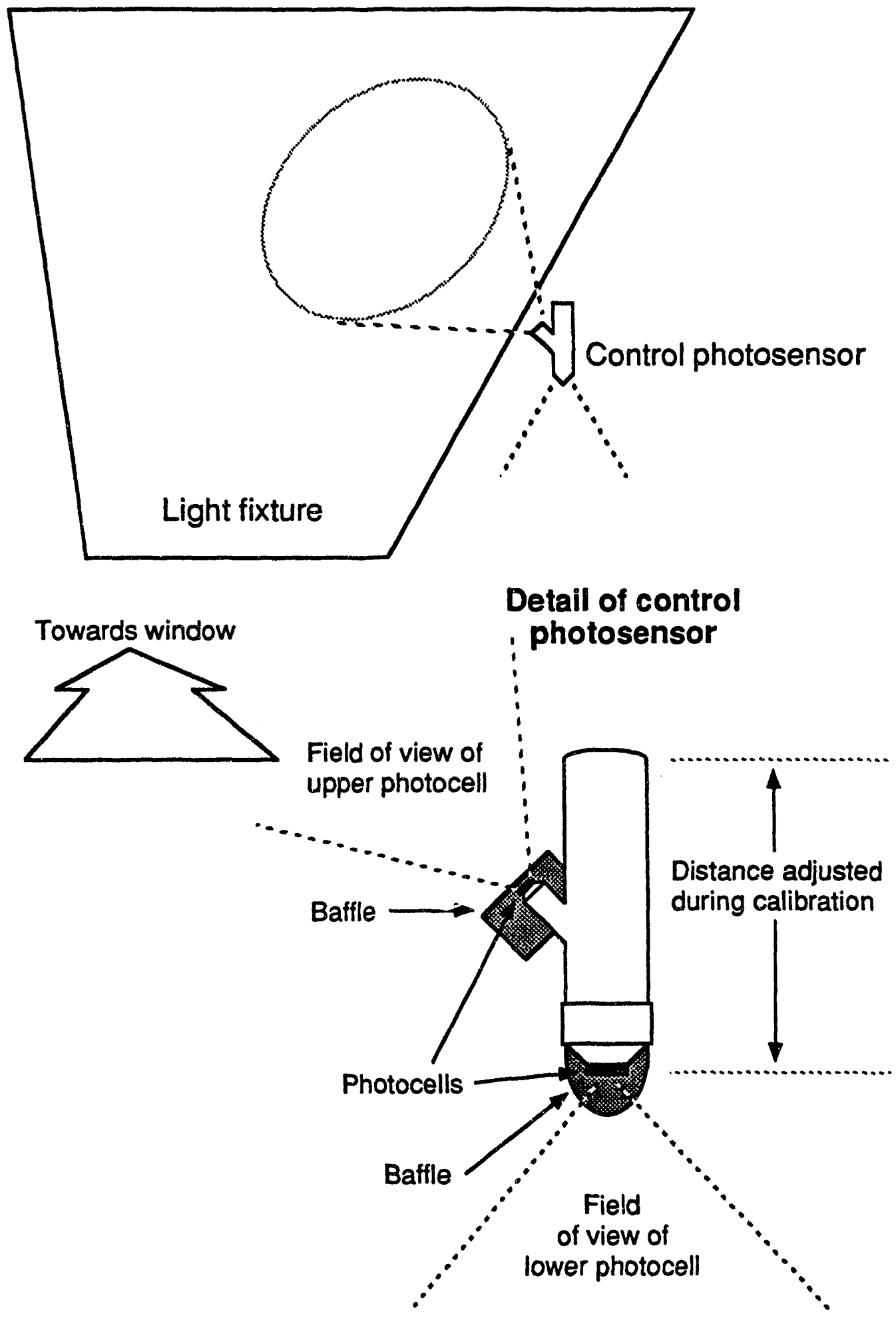

Figure 2-3. Location of control photosensor relative to fixture. 
arriving at the task surface (see Rubinstein et al. 1989 for a more complete discussion of this topic). The upper photocell is sensitive to the brightness of the nearby electric light as determined by the angle of acceptance of the photocell. By raising or lowering the stalk, the relative contribution of the upper sensor to the total signal can be varied. When the stalk is lowered, the output of the upper photocell will increase because it sees a larger area of the lamps; the output of the lower photocell remains essentially constant. Calibrating the response of the photo-control system consists of adjusting the height of the stalk and trimming the set point level to the correct value for the specific lighting conditions. This calibration is required to maintain the designed illumination level at the task for each area. The calibration process is described in detail in Section 3.

\section{LAYOUT OF CONTROL GROUPS}

For lighting control systems, the building lighting system must be subdivided into appropriate control groups. A "control group" is defined as a group of lights that are controlled together to supply the same illumination level. Generally, these control groups are organized to accommodate the functional requirements of a desired combination of strategies. For example, to use available daylight effectively, control groups should generally run parallel to the window walls. In a retrofit situation, existing lighting wiring may have to be preserved to minimize installation costs.

Often, a control group corresponds to a portion of a branch circuit or the entire circuit. At the Watergate Tower 1, both the daylight distribution from the vertical glazing and scheduling requirements had to be accommodated. Since the daylight workplane light levels drop rapidly as one moves away from the window (especially in the partitioned south zone), each string of lights running parallel to the window walls was controlled. The existing branch circuit wiring dictated that pairs of these control strings be operated off a single branch circuit. As shown in Figure 2-2, this grouping formed six independently controllable strings of lights energized by three branch circuits (circuits 9,11 , and 16). The control strings were numbered from 1 to 6 and will be referred to as such throughout this report. Circuit zone 9 served the area immediately next to the south window wall (South daylit zone) and encompassed control strings 6 (nearest the window) and 5 . Circuit zone 11 is the interior area on the south side (south interior zone) and includes control string 3 and control string 4, which is directly over an aisleway. Circuit zone 16 served the area next to the north windows (north daylit zone) and included control strings 1 (nearest the window) and 2.

Each control string requires at least one photocell input for daylight and/or lumen maintenance control. We used two photocells per string with photocells mounted near the ends of each string. The exact photocell position is dictated by practical considerations such as avoiding locations that may be susceptible to spurious light reflections (e.g., sunlight reflecting off plastic printer covers). 
In addition to the six control strings, we established another area, circuit zone 18, to serve as a reference zone against which to compare the performance of the controllable zones. Although such a group would ordinarily be termed a control group, we use the term "reference zone" throughout this report to avoid confusion.

\section{INSTRUMENTATION}

\section{Electrical Measurements}

The lighting power and current to the four branch circuits serving the demonstration site (including the reference zone) were monitored with power and current transducers installed in the electric room. These transducers accurately measure true root mean square (RMS) power and current regardless of any current wave shape distortion. All the transducers were mounted in an electrical enclosure mounted adjacent to the lighting circuit breaker panel. These watt and current transducers were recently checked for linearity and calibrated at the LBL Meter Shop.

Mes suring the power at the branch circuit level was the easiest and most convenient method for determining lighting energy use. Because each branch circuit encompassed two control strings, we could only determine the total power to pairs of control strings rather than the power to each string individually.

\section{Photometric Measurements}

Light levels at various locations in the site were monitored with an array of photometers on the north and south zones. These color-and cosine-corrected photometers, Li-Cor Model 210S, were used for monitoring purposes only and should not be confused with the ceiling-mounted photocells used by the dimmable lighting system to control the electric light levels.

North side. To get a representative measure of the daylight levels at varying distances from the north windows, five photometers were mounted in a linear array perpendicular to the north window wall. Four of the five photometers were affixed on 4-ft centers to a low partition separating rows of desks. The photometer nearesi the window was approximately 8 inches from the inside window surface, while the outermost photometer was $12 \mathrm{ft}$ further in. In addition to these four photometers, we mounted one photometer directly to the window pointing outwards. This photometer provided a measure of the vertical daylight illuminance on the window. (See Figure 2-2.)

South side. The presence of tall partitions in the south zone complicated installation of the photometric array. At other demonstration sites (Benton 1989) with partitions, ambient light levels have been monitored with photometers mounted atop the partitions. At Watergate, however, the lighting system (i.e., the 
dimmable electric lights and daylight) is intended to supply all lighting needs at the task, not just the ambient, level. Consequently, we elected to mount photometers at desktop height directly to the edge of selected partitions. (See Figure 2-2.)

\section{Temperature Measurements}

Since fluorescent lighting systems are sensitive to changes in a:nbient temperature, a typical lighting fixture in the south daylit zone was instrumented with thermocouples to measure temperature in three locations:

1. Minimum lamp wall temperature. The thermocouple was glued to the bottom of the outer lamp.

2. Lamp compartment ambient temperature. The thermocouple was positioned in the lamp compartment approximately 1 inch from the outer lamp.

3. Plenum temperature. The thermocouple was positioned approximately 1 inch above the top of the fixture protruding into the plenum space.

The location of the fixture instrumented with thermocouples is shown in Figure 2-2.

\section{Data Acquisition}

The power and current transducers measuring the lighting circuits were recorded using a Campbell Scientific 21X Data Acquisition and Control Unit (12-bit precision). The CR-21X recorded instantaneous outputs from all the watt and current tran'sducers every 10 minutes.

Additional CR-10 Data Aco!jisition Units were used to measure the outputs of the five photometers in the north zone and the three photometer outputs and three thermocouples on a lighting fixture in the south zone. These CR-10s were programmed to scan all the photometers (and thermocouples) every minute and to store averages and standard deviations every 10 minutes.

\section{Selection of the Baseline}

To assess the impact of any lighting conservation measure on energy use, the energy performance of the lighting system must be compared with the conservation measure installed to an equivalent portion of the building where the measure is not installed (the baseline condition). With lighting controls, selecting the baseline condition can be difficult because lighting usage patterns vary from day to day and season to season. Thus using end-use data from a zone prior to installing controls for the baseline condition may not give an accurate picture of the energy savings. Alternatively, one can select a different portion of the building to serve as the baseline and then compare the energy use in this zone to the zone(s) where the controls 
are installed; this approach is problematic because a different portion of the building has different people working there and may have different usage patterns than the other zones.

In presenting the daily lighting energy-use data and the lighting power profiles from this demonstration site, we used the lighting energy usage in the reference zone as the baseline condition. However, in the energy savings summaries at the end of Section 3, we applied a correction factor to the baseline zone data to account for the fact that the reference zone contained only 17 fixtures whereas all the zones with controls had 18 fixtures.

\section{INSTALLATION}

The lighting controls were installed in May 1989: the existing 2-lamp ballasts were replaced with 3-lamp electronic ballasts in all the fixtures in the six control strings. Control wiring was run to each fixture in a string and wired back to the controller boards in the electric room. Two control photosensors were installed for each control string and the photosensor wiring was run back to the electric room. Maintenance consisted of simply wiping out any dirt in the fixtures and relamping with new 40-W standard cool white fluorescent lamps.

Since the fixtures in place used four lamps (one 2-lamp ballast running the inboard tubes with the second operating the outboard lamps) it was necessary to remove one lamp to accommodate the 3-lamp electronic ballast. Although this would seem to imply a compromise in light level, an electronic ballast can provide more light for the same input power than a conventional, energy-efficient core-coil ballast. Moreover, these particular ballasts have a relatively high ballast factor (between 1.07 and 1.08 as measured in lab bench tests), and we replaced 34-W lamps with 40-W lamps that produce proportionately more light. Since the ballast factor for the original 34-W lamp/ballast system was only 0.87 , we anticipated little change in fixture light output.

In addition to the measures undertaken in the six control strings, the maintenance crew also wiped out any dirt in the fixtures in the reference zone and relamped with new 34-W cool white lamps.

To take advantage of the lumen maintenance control strategy in calibrating the lighting control system after relamping the lights in the control zones, we had to adjust the output to some value below the full light output level that they could provide. (If the light levels were simply set to full, the control system would have no "throttling range" left to maintain constant illuminance as the liahting system aged.) The level to be set is, to some extent, a judgement call since we did not relamp at the same time that maintenance would ordinarily occur. Measurements of light levels in the reference zone indicated that light levels increased about $33 \%$ 
(from 45 to $60 \mathrm{fc}$ ) after cleaning and relamping. Consequently, we decided to set the light levels in all the control zones to approximately $75 \%$ of full light output (approximately $75 \%$ of maximum power, since for this system, light and power change proportionately). Stated another way, we set the light levels to be provided after installing the controls and relamping to approximately the same level that was in place before the retrofit. In most areas this was approximately $45-50 \mathrm{fc}$.

\section{Occupant Notification}

Prior to commissioning the control in May 1989, we alented the building occupants in the control and reference zones about lighting system modifications. The occupants were also given instructions for activating the lighting system in their zones with the telephone override system. Prior to implementing the load-shedding scenario in December 1990 (see Section 3 for results), the occupants were notified that a load-shedding experiment would be conducted during that month. In January 1991 following the loadshedding experiment, we asked the occupants for their comments on that experiment and their impressions of the lighting control experiment in general. This was not intended to be a comprehensive survey of the occupant response but rather to see if there were any major complaints about the light levels provided.

\section{Photosensor Callbration Procedure}

Calibrating the response of the photosensors is a critical step in establishing a properly responding, photoelectrically controlled lighting system. Experience at the Lockheed building in Sunnyvale, California (Benton 1989), has shown that the savings potential of a daylight-responding lighting system can be severely compromised without proper calibration and maintenance. In the present demonstration, proper calibration was especially critical since, unlike the Lockheed building, we were using a unique photosensor sysiein that could both compensate for lumen depreciation changes and respond to available daylight.

To calibrate the system's response, we first selected the specific locations (i.e., the control points) where we would provide the design light level. (Because the daylight levels drop rapidly as one moves away from the window, it is a physical impossibility to provide the design light level everywhere.) For simplicity, the control points were chosen to be $2.5 \mathrm{ft}$ above the floor (desktop height), immediately underneath each ceiling-mounted control photosensor. Since there were two ceiling-mounted photosensors per control string, there were also two control points per control string.

We performed the calibration at a time when the daylight contribution to the total illuminance at each control point was less than the design level of $50 \mathrm{fc}$. This assured that some electric lighting would be necessary to supply 50 fc of total illumination at the control point. ${ }^{4}$ With the electric lights off, we recorded both the

\footnotetext{
A design light level of 50 ic (538 lux) was selected to be consistent with lighting levels provided in the reference zone.

00819121/918443/ppu276

$2-13$
} 
daylight illuminance at the control point using a hand-held photometer and the voltage output from the control photosensor. From this measurement, the control photosensor set point level is determined. ${ }^{2}$ For example, if the control point illuminance was $30 \mathrm{fc}$ and the photosensor output was $1.4 \mathrm{~V}$, then the control photosensor set point level was $2.33 \mathrm{~V}(50 \mathrm{fc}+30 \mathrm{fc} \times 1.4 \mathrm{~V})$. A trim pot in the controller was adjusted to make this voltage the set point voltage. Once the set point level was calculated and set, the photosensor's sensitivity had to be adjusted to electric light relative to daylight by adjusting the distance that the control photosensor projected below the ceiling plane (see Figure 2-3). This was accomplished by turning on the electric lights in the zone, setting the controller to automatic closed-100p control, and measuring the resultant total illuminance at the control point. If the light level at the control point was below $50 \mathrm{fc}$, we dropped the photosensor down a small amount. (The photosensor was raised a little if the light level was too high.) We measured the light level again and readjusted the photosensor depth until the design level was achieved. As a final check, we then closed the drapes to greatly reduce the daylight level and checked to make sure that the design light level was still provided.

\footnotetext{
2When properly calibrated, the set point level is the specific control photosensor output voltage that the system will attempt to maintain under all daylighting conditions by raising or lowering the electric light level. 


\section{A YEARLONG TROFILE}

This report presents data for the entire year of 1990, when all lighting control _trategies were used. To anaiyze the effeci of the integrated control strategies on lighting energy use, we calculated the lighting energy use per zone per day for each day of the year. For clarity of presentation, we split this dataset into weekulays and weekends because the usage patterns were significantly different. We then further subdivided the weekday datasets into daily lighting energy use during core operating hours only (6 A.M. to 6 P.M.) and lighting use over the entire day. Dividing the data in this manner effectively allows one to isolate the effect of scheduling-a strategy that (in this building type) only saves energy during noncore hours.

\section{Lighting Energy Usage on Weekdays}

The lighting energy use perweekday in 1990 is graphed in Figures 3-1 through 3-3 for the north daylit, south daylit, and south interior zones, respectively. In each case, the energy use for the zone is compared with the use in the reference zone. Several patterns immediately emerge from these graphs. First, it is apparent that the lighting energy use is consistently much lower in the zones with controls than in the reference zone. The north daylit zone (Figure 3-1) is particularly striking both as to large energy savings over the year as well as the obvious effect of the time of year on the energy usage. The usage in the north daylit zone averages $17 \mathrm{kWW}$ day during the summer but over $25 \mathrm{kWh} /$ day during the winter. The effect of the time of year on the energy use in the north zone is even more apparent in the core-hour data (Figure 3-1B) because the data are undiluted by the effect of after-hours usage. The effect of time of year is far less noticeable for the south daylit zone, which has only slightly lower usage during the summer than during the winter months, even for the core-hours only data (Figure 3-2B).

Despite the seasonal similarity, the north daylit zone shows lower usage at the beginning of the year than at the end of year because the control system compensates for lumen depreciation. Since the lamps were older at the end of 1990 and therefore produced less light, the control system compensated by slightly increasing the energy usage to provide a constant illumination level throughout the year. This, of course, is exactly how the lumen maintenance strategy is supposed to work. However, to our knowledge, this is the first time that this strategy has been conclusively demonstrated in a "real" building. Furthermore, the results indicate that the photosensor control technique adopted in this demonstration both compensates for changes in available daylight and corrects for lumen depreciation. Lumen maintenance is discussed further in Section .r.

$00819121 / 918443 / p p u 276$ 

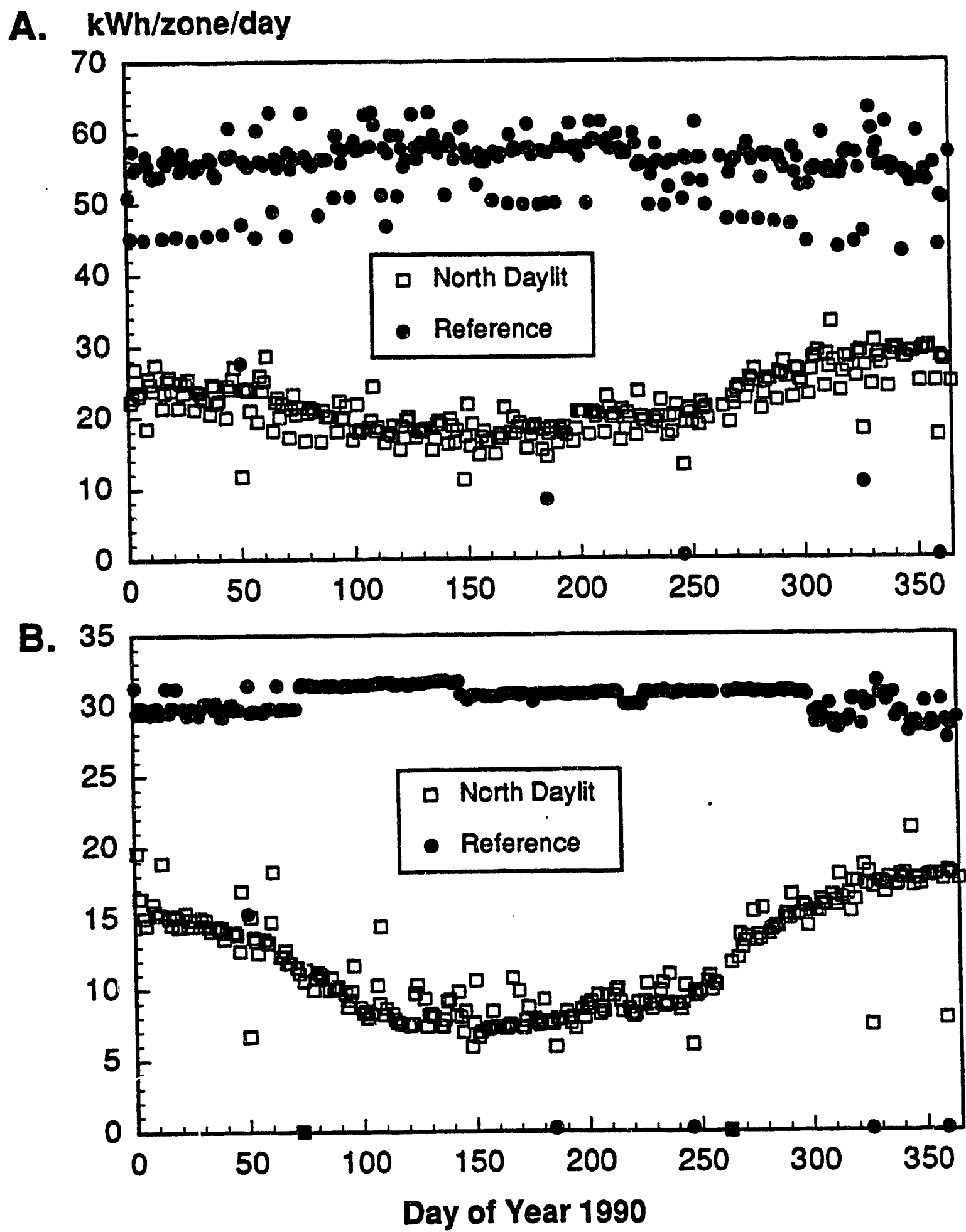

Figure 3-1. Plot of daily energy use on weekdays for north daylit zone compared to usage in reference zone. Upper plot (A) shows energy usage computed over entire day (midnight to midnight). Lower plot (B) shows usage computed for core hours only (6 A.M. to 6 P.M.). 
A. kWh/zone/day

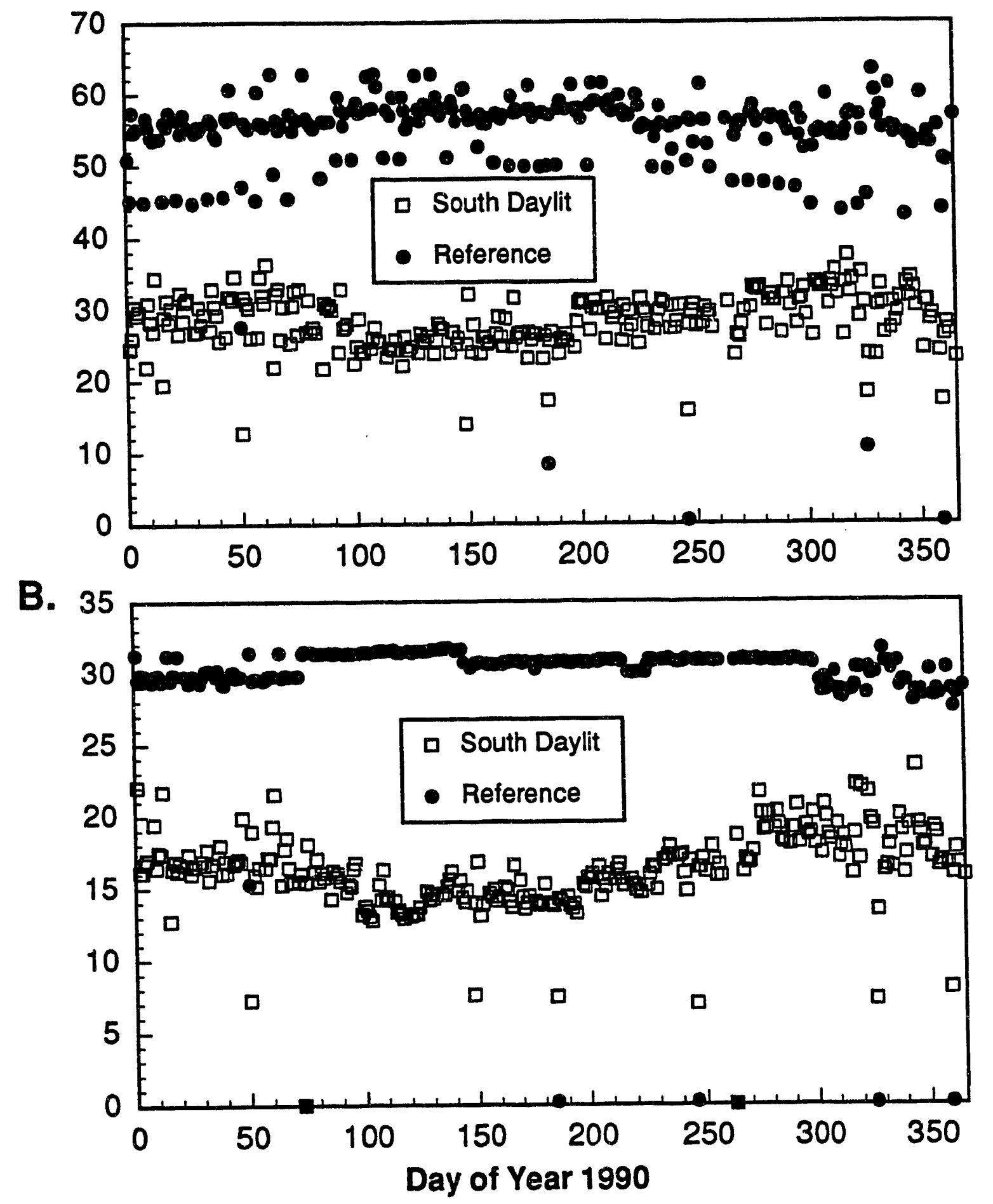

Figure 3-2. Plot of daily energy use on weekdays for south daylit zone compared to usage in reference zone. Upper plot (A) shows energy usage computed over entire day (midnight to midnight). Lower plot (B) shows usage computed for core hours only (6 A.M. to 6 P.M.). 
A. kWh/zone/day
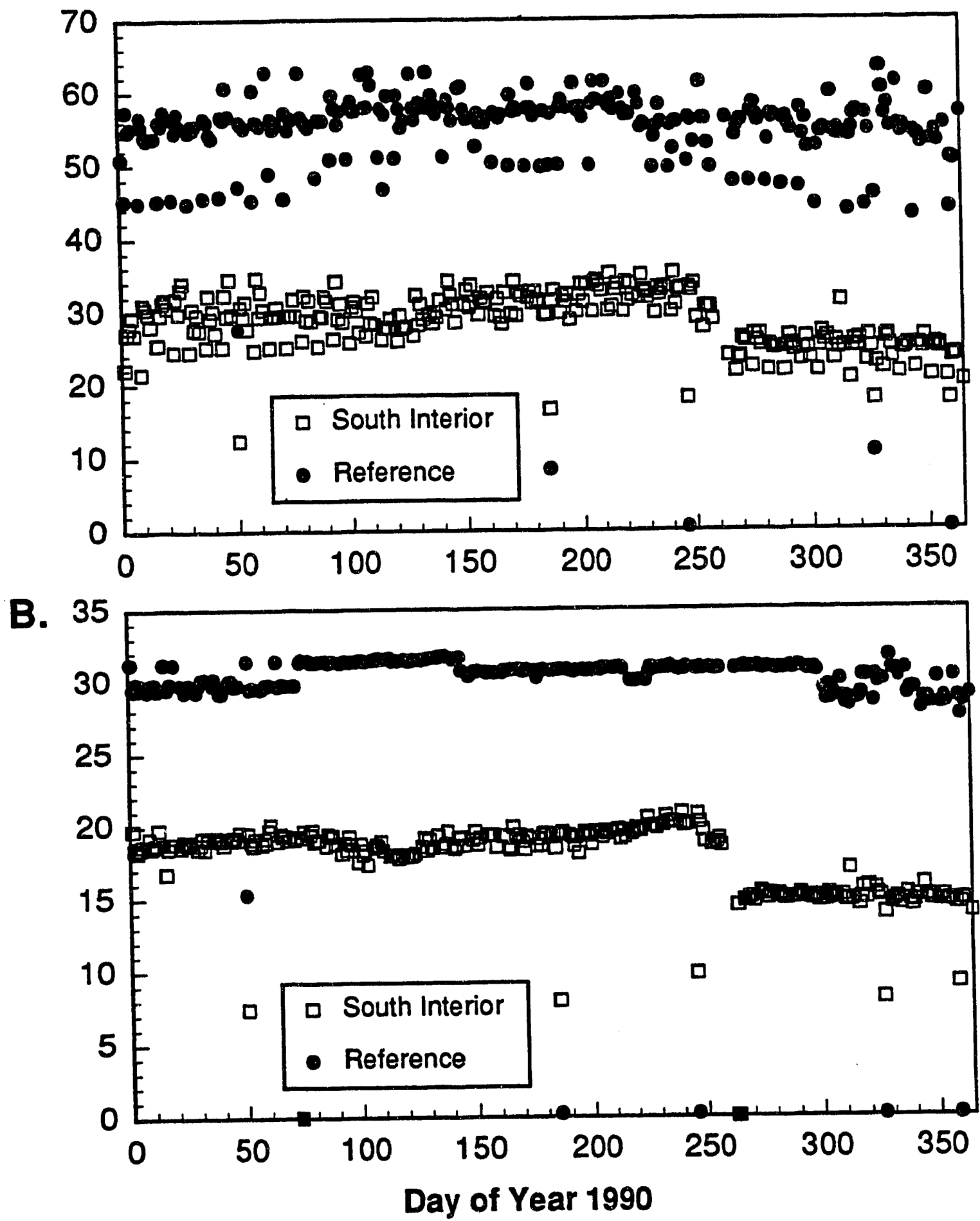

Figure 3-3. Plot of daily energy use on weekdays for south interior zone compared to usage in reference zone. Upper plot (A) shows energy usage computed over entire day (midnight to midnight).

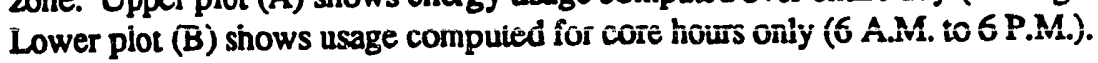


The large drop in energy usage in the south interior zone during the fall is due to the fact that the lights over the aisleway in the south zone were tuned to one-half level on September 23 and were left that way for the remainder of the year. Tuning is discussed further in Section 4.

\section{Lighting Energy Usage on Weekends}

The lighting energy usage on weekend days for all zones is plotted in Figure 3-4. This plot shows that the energy usage on weekends is very variable in all zones. Despite this variability, it is clear that far less lighting energy was used in all the control zones than in the reference zone. In fact, the energy usage in the reference zone is sometimes higher than on weekdays because the lights in this zone were sometimes left on the entire day. This never occurred in the control zones because the lights were programmed to sweep off every three hours.

\section{TYPICAL DAY LIGHTING POWER USAGE}

Having shown the daily energy-use patterns for all the data collected for 1990, we now present the lighting power as a function of time of day for representative days of the year. These lighting power profiles are given in Figures 3-5 through 3-7 for days near the spring equinox and the summer and winter solstices.

In all cases, the lighting power consumed in the zones with controls is significantly less than that in the reference zone. (The "sawtooth" profile observed in the power plot for the reference zone is due to a cycling thermal protection switch in one of the magnetic ballasts. When the HVAC system is off, the plenum heats up sufficiently to cause that one ballast's thermal switch to cycle. The ballast does not usually cycle during the daytime hours since the HVAC is on and keeps the plenum cooler).

The plots indicate that there is significant dimming occurring in the north and south daylit zones throughout daylight hours at all days of the year, while the power reduction in the south interior is generally minimal due to the distance of this zone from the windows. While the power profiles for the north and south zones are reasonably similar during the winter, greater reductions are seen in the north zone compared to the south zones during the spring and fall. Even during non-daylight hours, the lighting power use in all the control zones is lower than the reference zone. This difference is due to two factors: (1) the light levels after the retrofit were set to approximately the same as before the retrofit rather than to maximum light output, and (2) the electronic ballasts are more efficient than the energy-efficient core-coil ballasts they replaced.

The lighting load in the zones with controls did not drop to exactly zero between 2 A.M. and 5 A.M. This small but nonzero load is attributable to the fact that, when the lights are commanded to zero, some residual power 


\section{kWh/zone/day}

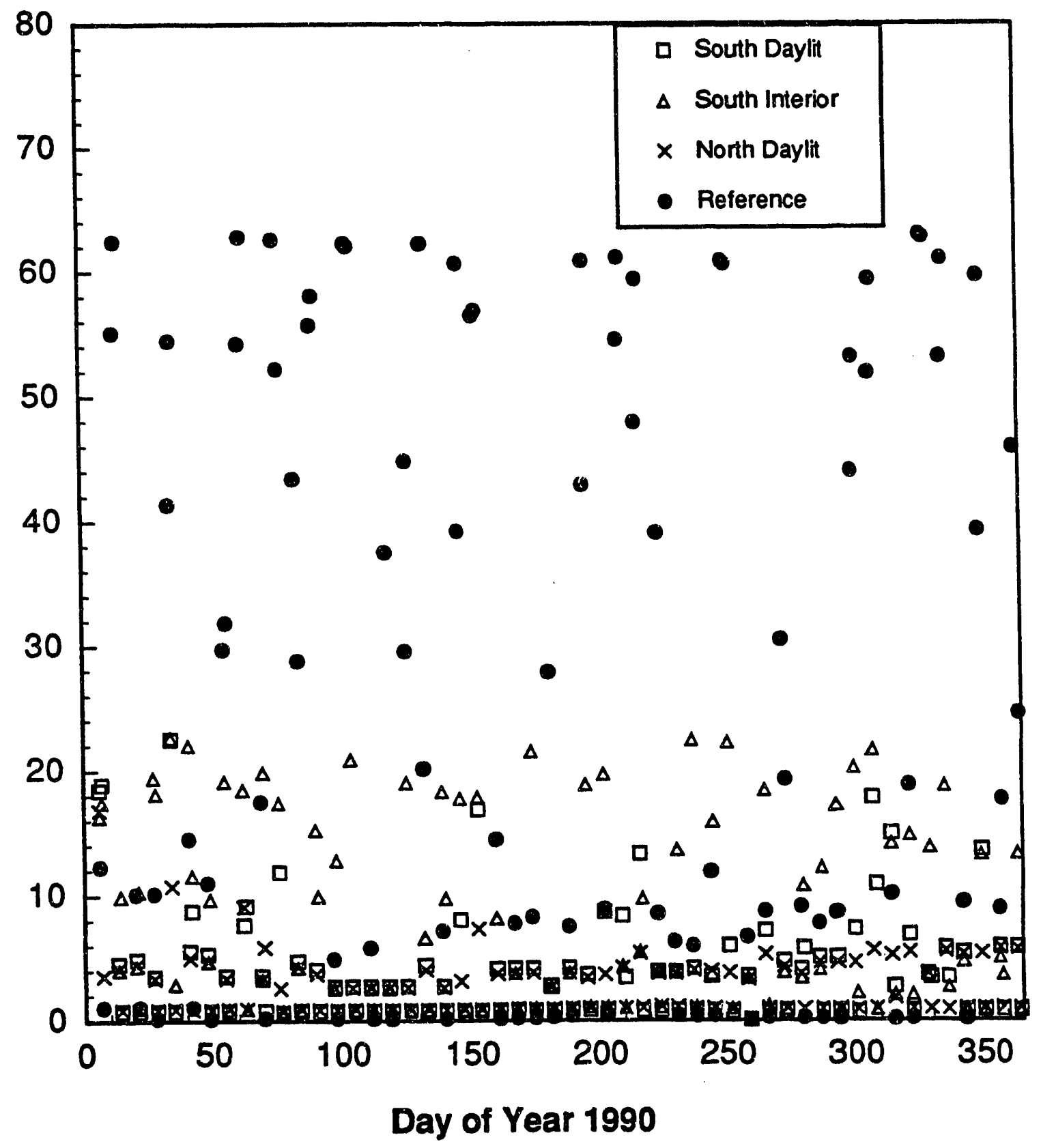

Figure 3-4. Plot of daily energy use on weekend days for north daylit zone, south daylit zone, and south interior zone compared to usage in reference, zone. Daily usage is computed for entire day (midnight to midnight). 


\section{Lighting Power (kW)}

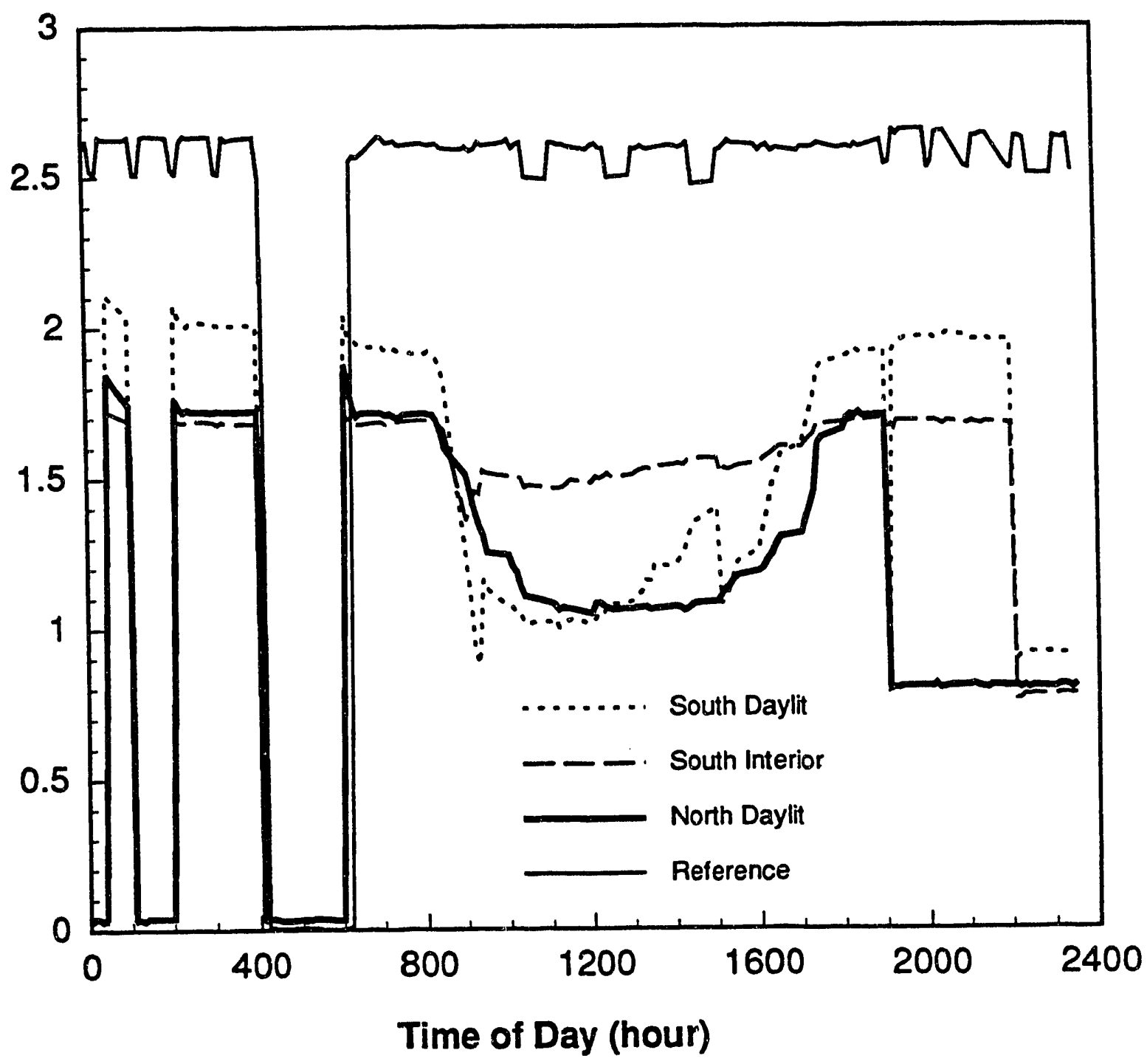

Figure 3-5. Lighting power in all zones for typical weekday (January 9) near the winter solstice. (The "sawtooth" pattern seen in the power for the reference zone is due to a cycling thermal protection switch in one of the magnetic ballasts in that zone.) 


\section{Lighting Power (kW)}

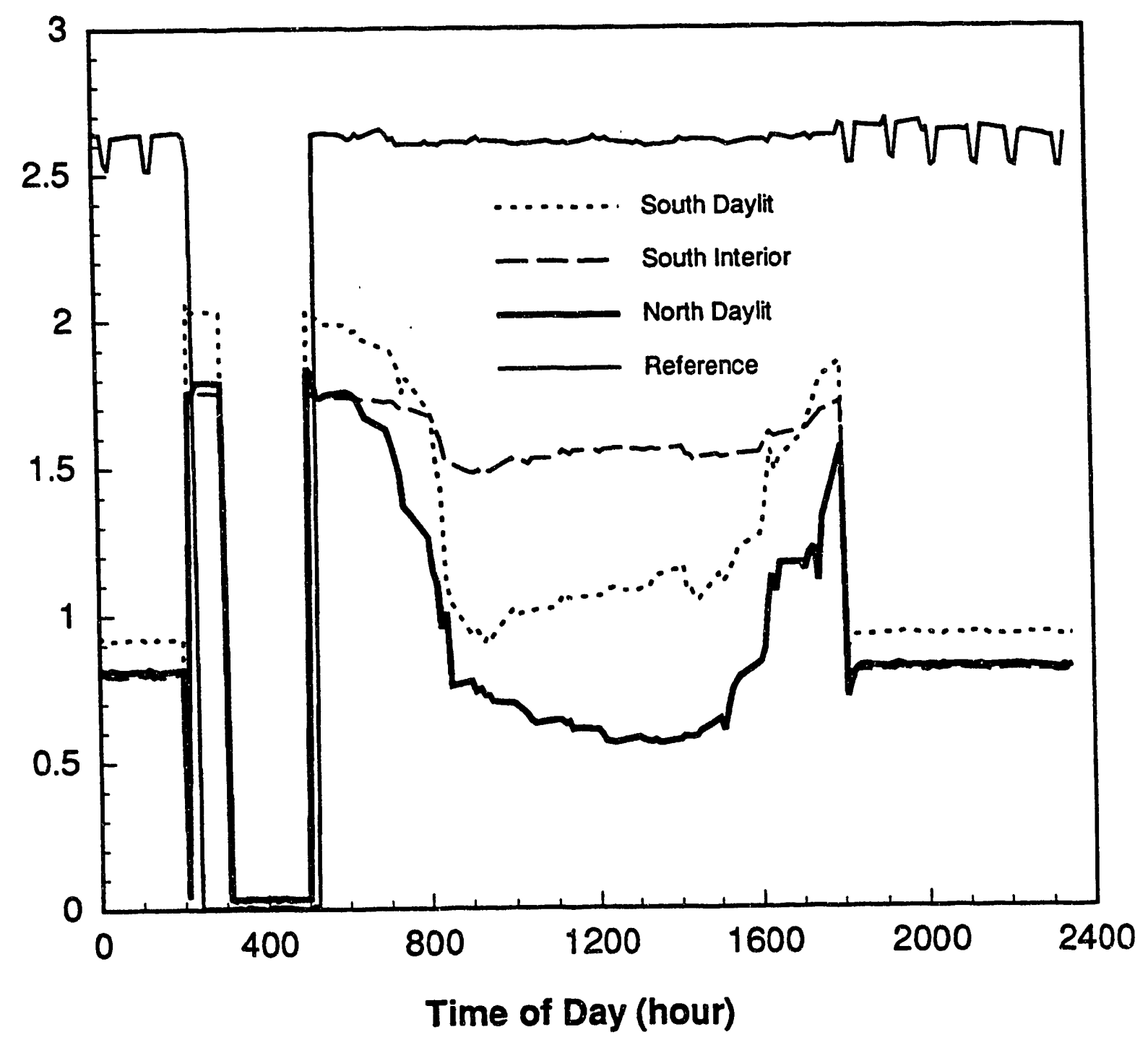

Figure 3-6. Lighting power in all zones for typical weekday (March 23) near the spring equinox. 


\section{Lighting Power (kW)}

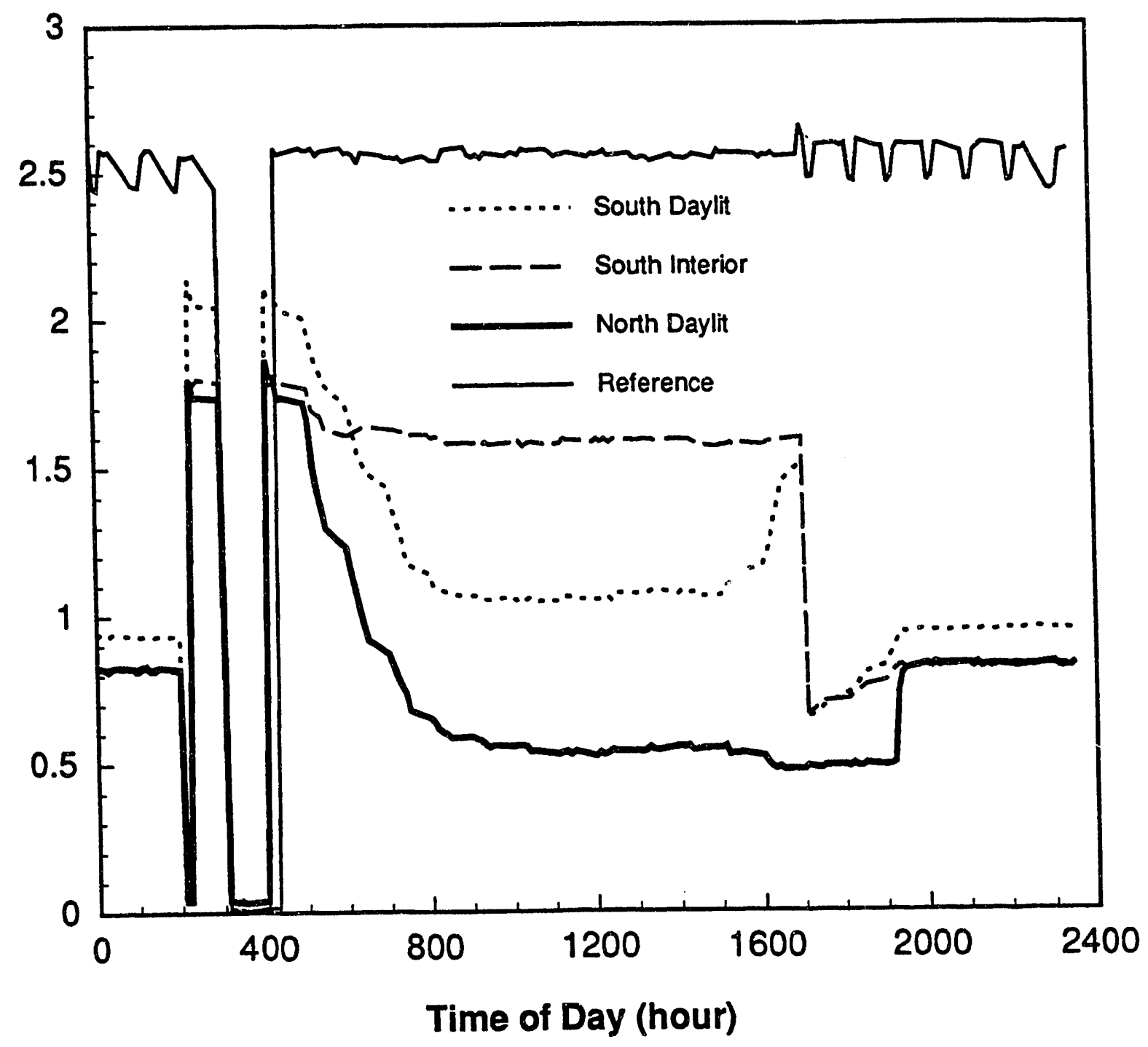

Figure 3-7. Lighting power in all zones for typical weekday (June 20) near the summer solstice. 
is still consumed by the ballasts even though lamp power is zero. This is clearly a very small effect and is dwarfed by the energy savings.

\section{EFFECT OF DRAPES ON ENERGY SAVINGS}

To illustrate why the energy savings in the south daylit zone were less than that measured in the north daylit zone, we present a plot of the lighting power usage in the south daylit zone for one day (Figure 3-8). The lighting power usage drops precipitously at the beginning of the day (i.e., between 8 A.M. and 9 A.M.) as the direct sun starts to penetrate the south-facing windows, and the control system responds by dropping the supplied electric light level. Because of the glare and thermal discomfort, the occupants close the drapes at around 9:00 A.M. This greatly reduces the glare but also causes the control system to supply more light and increase energy use. At the end of the day (i.e., around 4:00 P.M.), the lighting power usage drops again when the occupants open the drapes. This pattern of usage was often observed for the south zone. In the north zone, however, the sun only rarely penetrates the windows (and then only at the very end of the day after most individuals have left).

\section{ENERGY SAVINGS WITH DAYLIGHTING ALONE}

To estimate the energy savings attributable to daylight-linked control independent of the savings from other strategies, we have used the lighting power data measured on March 23, 1990. Since this day is near the spring equinox, the lighting system's performance on this day can be considered an average for the entire year. Using the curves from Figure 3-6, we calculated the lighting energy use in each of the three control zones between the hours of 6 A.M. and 6 P.M. and compared these values to the energy that would have been used in each of these zones if the lighting power were constant at 1.76,1.97, and $1.74 \mathrm{~kW}$ for the north daylit, south daylit, and south interior zones, respectively, throughout this 12 -hour period. (The constant values are slightly different in the various zones due to differences in calibration.) This calculation shows that the energy savings attributable to daylight alone was $48 \%$ in the north daylit zone, $33 \%$ in the south daylit zone, and $9 \%$ in the south interior zone. Note that these values should be used with some caution. The day analyzed was a clear day; the energy savings would be somewhat lower on a cloudy day. We have done the calculation between 6 A.M. and 6 P.M., not over the day. If we had done the calculation over the entire Jay, the energy savings would, of course, be smaller. However, this method is probably more useful for estimating the energy savings potential of daylighting in new buildings where, because of increased local switching requirements, the lighting hours of operation may be less than in older buildings.

\section{ADDED EFFECT OF TUNING}

Since September 1989, we had implemented daylighting, scheduling, and lumen maintenance in all the control zones. Because the savings due to daylighting was only marginal in the interior south zone, in 


\section{Lighting Power (kW)}

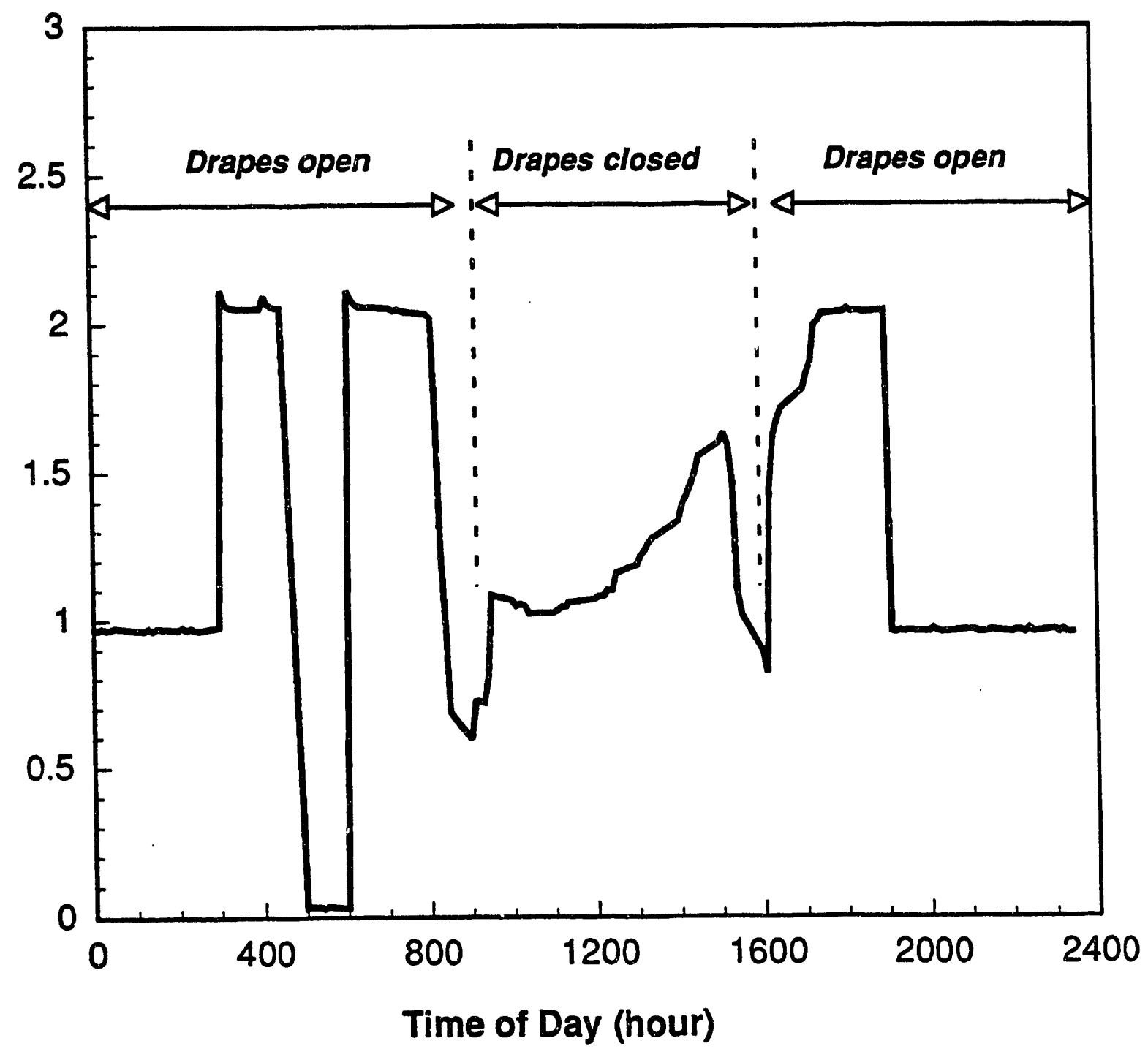

Figure 3-8. Effects of drapes on lighting power in south daylit zone for a typical clear day (November 27, 1990). 
September 1990, we implemented the tuning control strategy in the south interior zone by reducing the output of control group 4. This string of lights is directly over the aisleway and contributes little useful light to nearby work surfaces.

To obtain a more accurate handle on the energy savings potential of this strategy independent of other strategies, we analyzed the energy use in the south interior zone for the 2-week period before and after tuning the aisleway lights to low level. (Note that although the south interior zone contains two strings of lights, only string 4 was tuned to a low level. The other string of lights could not be tuned down without negatively affecting productivity.) Before tuning, the average daily lighting energy usage (calculated midnight to midnight) was $30.5 \mathrm{kWh} /$ day. Aftei the aisleway lights were tuned down, the average daily lighting energy use dropped to $24.5 \mathrm{kWh} /$ day -a $19.6 \%$ reduction. Since only one string of lights was tuned, the reduction in that string was approximately $40 \%$.

\section{LOAD-SHEDDING TESTS}

Three lighting control strategies were implemented simultaneously in all the control zones until September 1990, when tuning was added to the palette of strategies being tested in the south interior zone. At this point, the only remaining lighting control strategy to be tested was load shedding-a strategy that modestly reduces lighting demand for short periods of time to lower peak demand charges. Because lighting loads would generally only be reduced a small amount (10-25\%) for a short period of time (i.e., less than

one hour), load shedding does not save much lighting energy, but rather is intended to reduce operating costs either by avoiding the incurrence of a peak-demand ratchet charge or by responding to a real-time pricing signal from the utility company. (The way in which we implemented load shedding at the Watergate complex, for example, would reduce daily lighting energy use by less than $1 \%$.) Practically speaking, if the strategy is intended to avoid a ratchet charge, a building demand monitor is required as input to an (intelligent) control system so that the system would know when to reduce light levels, how much to reduce them, and for how long. In addition, this strategy would probably be implemented so that nonlighting loads (such as fans and chillers) would also be shed on an appropriately prioritized basis. If, on the other hand, the strategy is implemented to be responsive to a utility's real-time pricing signal, then a link from the utility would be required. These schemes are still quite experimental, and we know of no commercial lighting control hardware/software packages that explicitly implement these schemes. Nonetheless, we wanted to examine the potential of a dimmable lighting control system for load-shedding control.

Since we had neither a building demand monitor nor a real-time pricing link to use as input to the control system, we simulated the input by arbitrarily dropping light levels in all control zones by about $15 \%$ for one hour a day between 2:00 P.M. and 3:00 P.M. on weekdays during December. To assess whether there was 
any occupant response to this strategy, we told the occupants what we intended to do (although we didn't tell them exactly when the light levels would be dropped). In January 1991, PG\&E sent a questionnaire to learn whether the occupants noticed any abrupt changes in light levels in the afternoon. Only $10 \%$ of the occupants noticed the drop in light level. Those that did described it as "mildly distracting." When we were demonstrating the drop in light level to six of the building management personnel, only one individual noticed the abrupt $15 \%$ change in light level even though they knew exactly when the change took place. Since the system changed light levels rapidly (in less than 2 seconds), we speculate that no one would have noticed the change if the system response were more damped.

The lighting power levels in all zones for one day during the month of the load-shedding test (December 13 , 1990 ) is presented in Figure 3-9. Light levels measured on the north daylit zone for the same day are presented in Figure 3-10. These figures indicate that both light and power were reduced by approximately $15 \%$ during the 1-hour interval between 2 P.M. and 3:00 P.M.

\section{LIGHT LEVEL MEASUREMENTS}

\section{North Zone}

The light levels measured by the monitoring photometers mounted at varying room depths in the north zone are shown on Figures 3-11, 3-12, and 3-13. The same days-January 9 and June 20-used for Figures 3-5 and 3-7 were also used for Figures 3-11 and 3-13. The photometer data for March 23 (Figure 3-6) were not available, so Figure 3-12 uses March 9. However, because the two days are at similar times of year and were similar in terms of sky conditions, they are comparable. It is significant that, despite the substantial electric dimming, the light levels remained relatively constant throughout the day. This is clear evidence that the daylighting controls were properly functioning by providing a reasonably constant illuminance at the workplane while permitting substantial reductions in lighting load. The light levels measured by the photosensor nearest the window are not constant, which is not due to any failing in the control system but rather to the distance of this monitoring photometer from the location at which the control system was calibrated (immediately under the control photosensors). All other things being equal, an equi-illumination lighting system will tend to oversupply illumination at locations that are closer to the windows than the stationpoint and will undersupply illumination at locations farther from the windows from the stationpoint.

\section{South Zone}

Light levels measured by the monitoring photometers in the south zone are given in Figure 3-14 for December 24, 1990. The reading from the photometer nearest the window wall ( $9 \mathrm{ft}$ in from the window) is off scale between 9:00 A.M. and 11:00 A.M. because this photometer has an unblocked view of the window and the daylight levels are quite high during this period. The photometer at $9.3 \mathrm{ft}$ from the window wall is 


\section{Lighting Power (kW)}

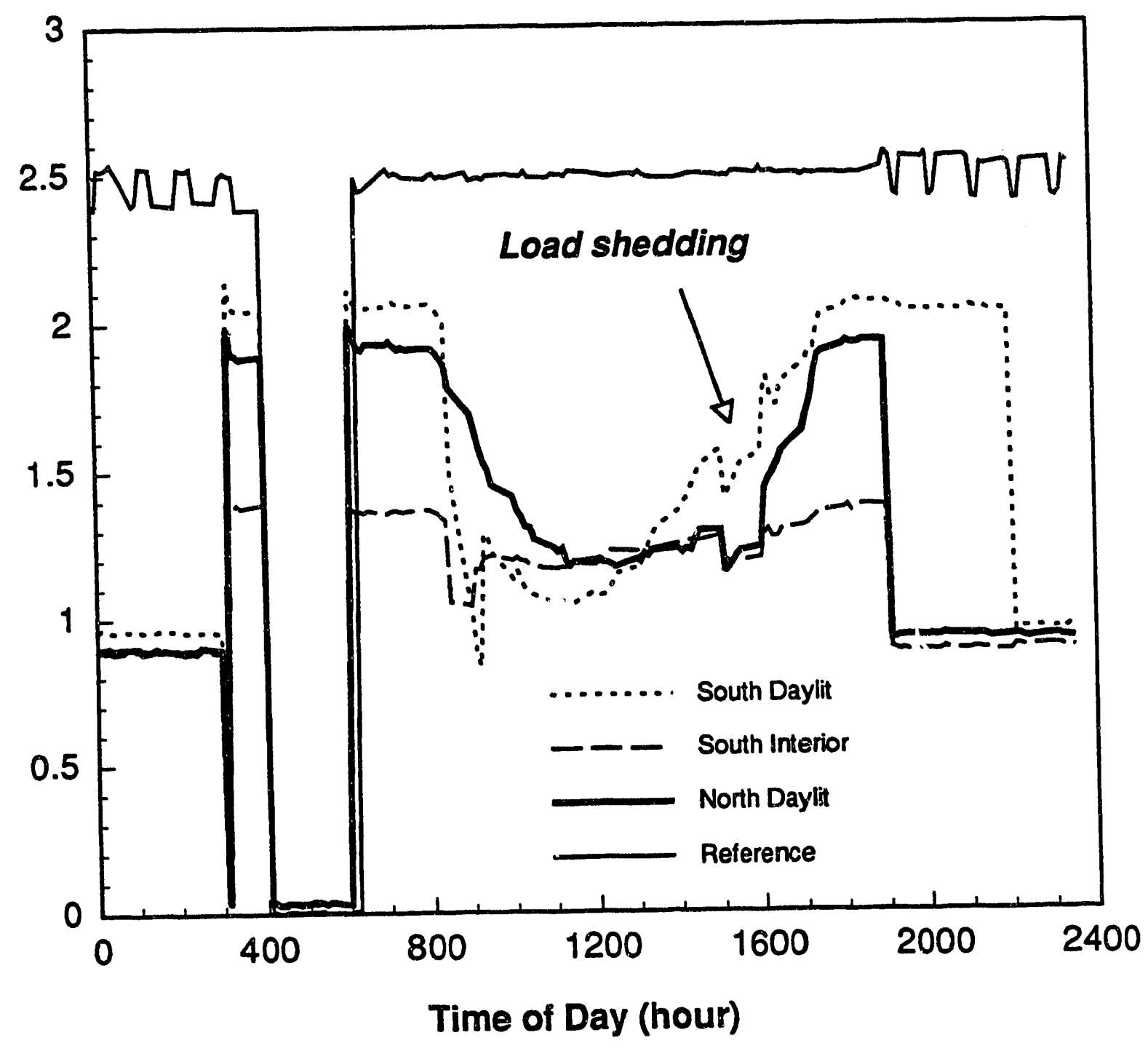

Figure 3-9. Effect of load shedding on the lighting power in all zones for a typical day (December 13, 1990). 


\section{Vlluminance (lux)}

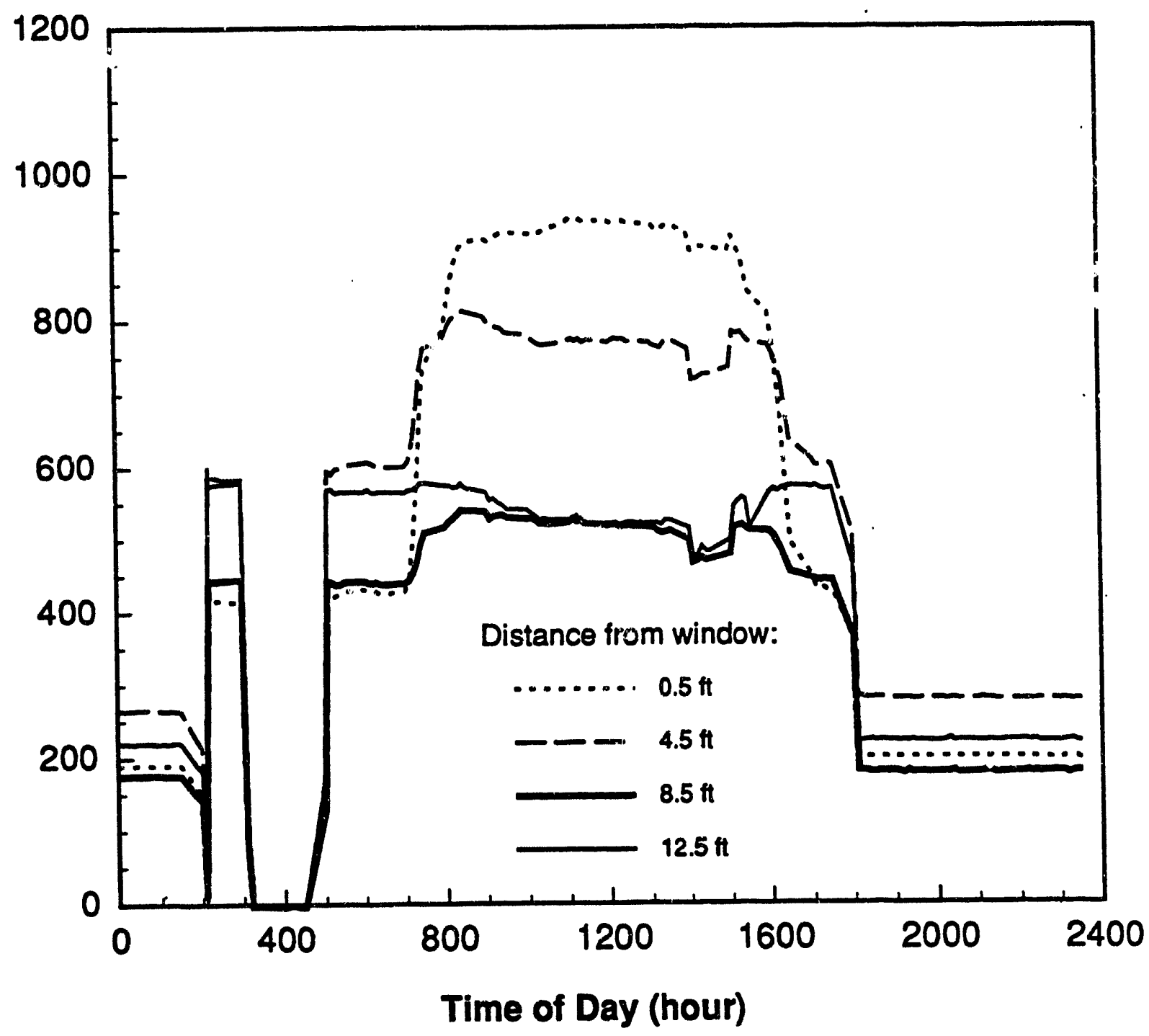

Figure 3-10. Workplane illuminance (42" above floor) at varying distances from north window for typical weekday (December 13, 1990) during load-shedding test. 


\section{Illuminance (lux)}

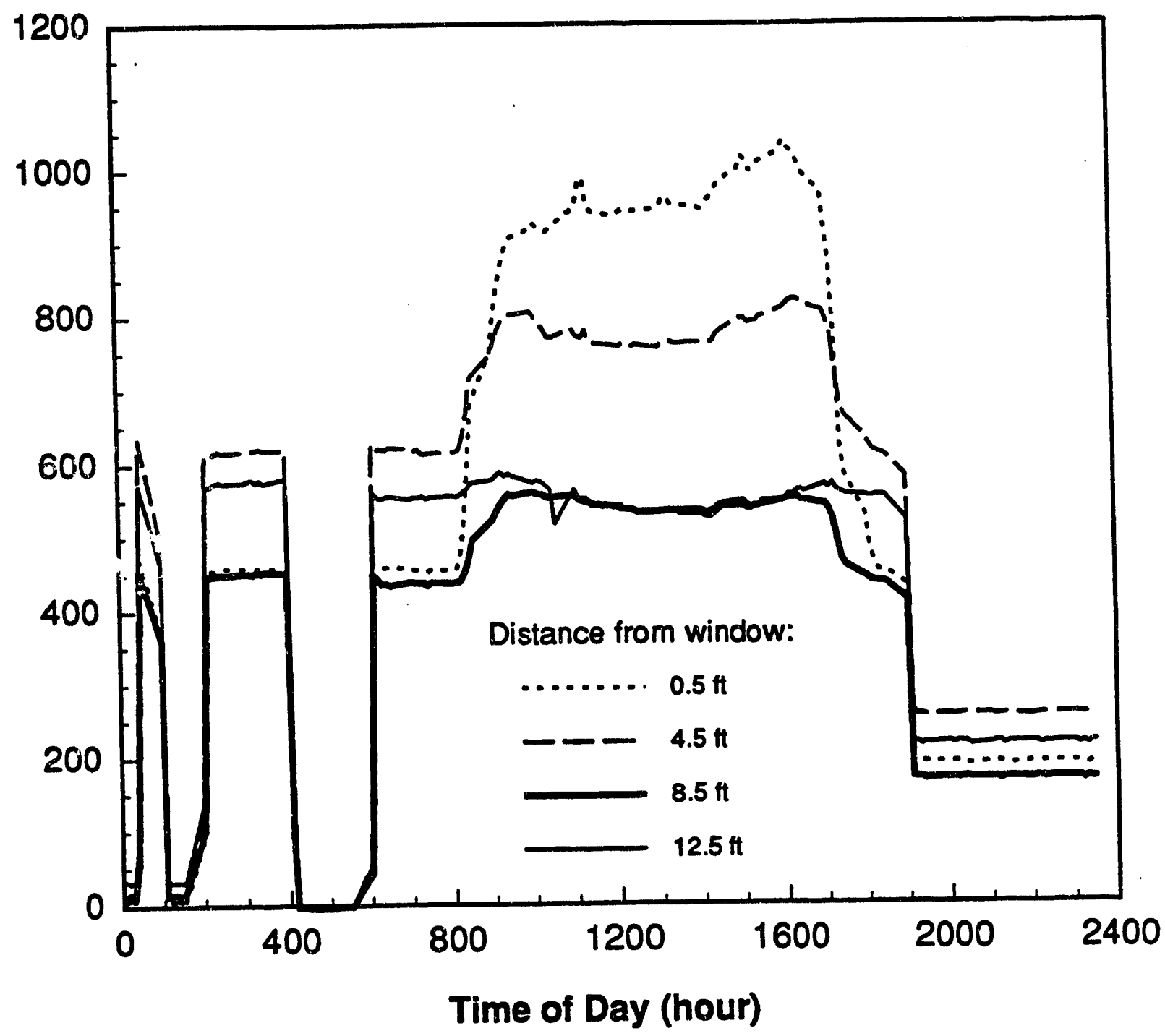

Figure 3-11. Workplane illuminance (42" above floor) at varying distances from north window for typical weekday (January 9) near the winter solstice. 


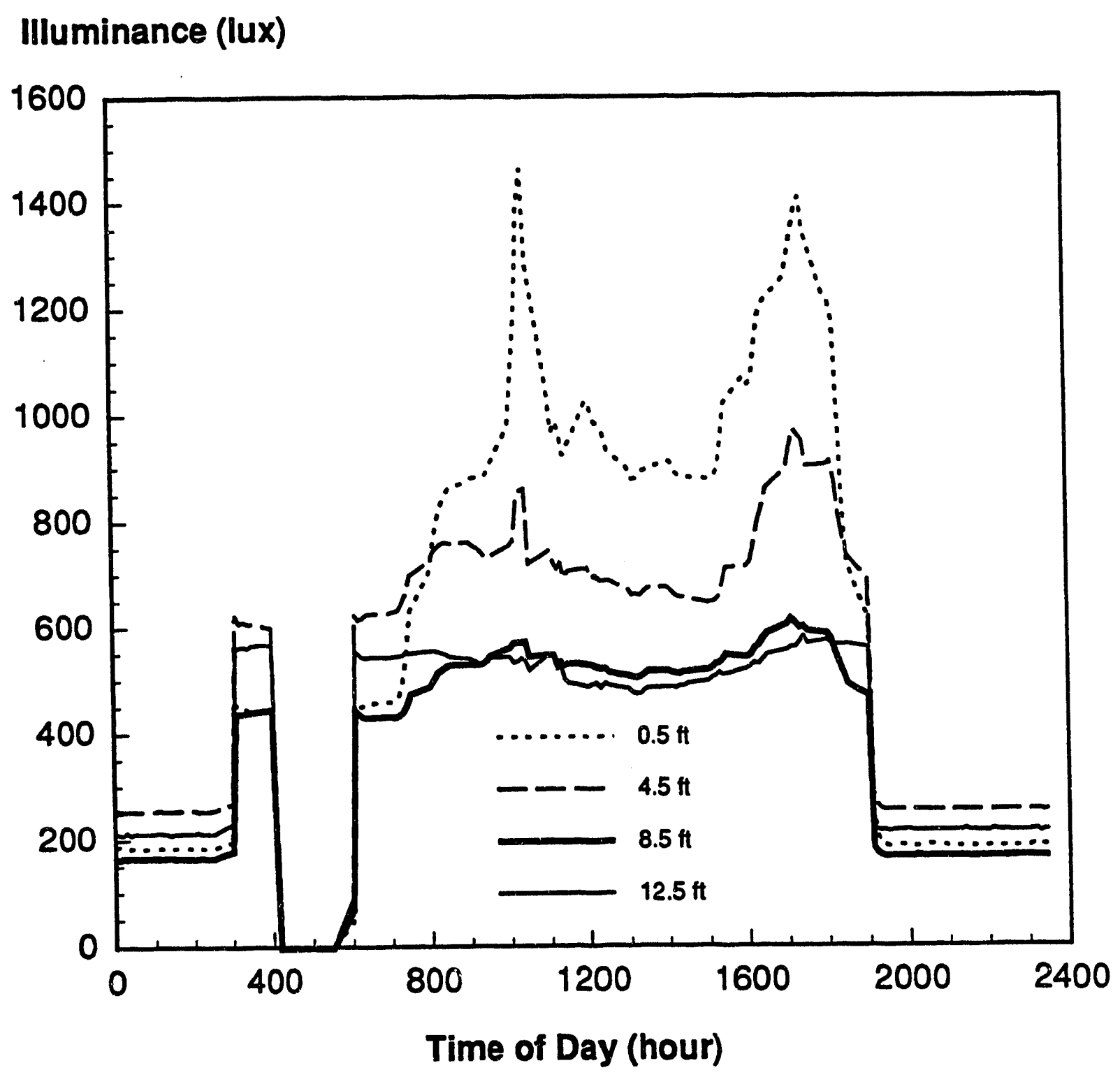

Figure 3-12. Workplane illuminance (42" above floor) at varying distances from north window for typical weekday (March 9) near the spring equinox. 


\section{Illuminance (lux)}

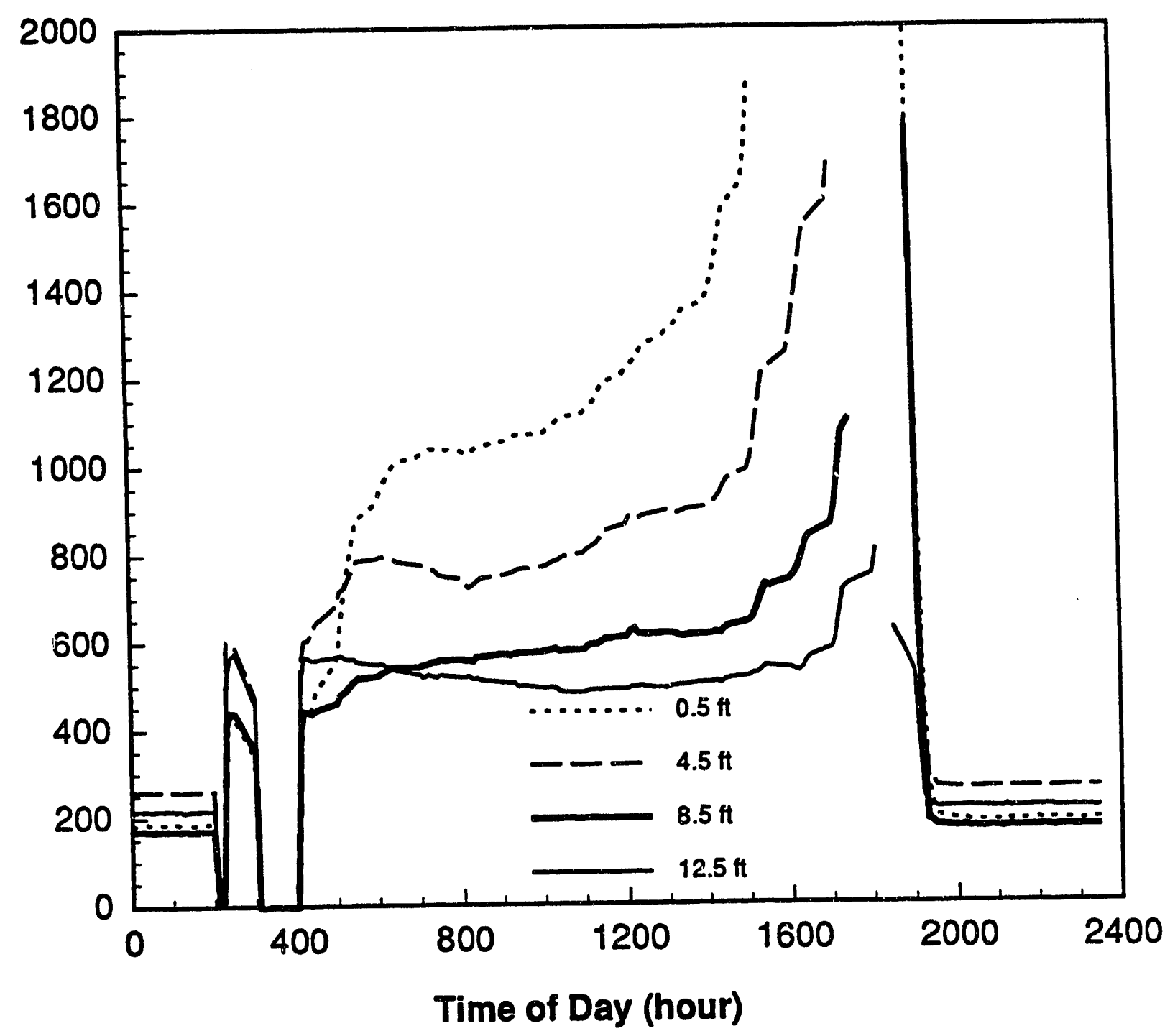

Figure 3-13. Workplane illuminance (42n above floor) at varying distances from north window for typical weekday (June 20) near the summer solstice. The missing parts of the curves are at times when the measuring instrumentation went off scale due to direct sun falling on the workplane photometers. 


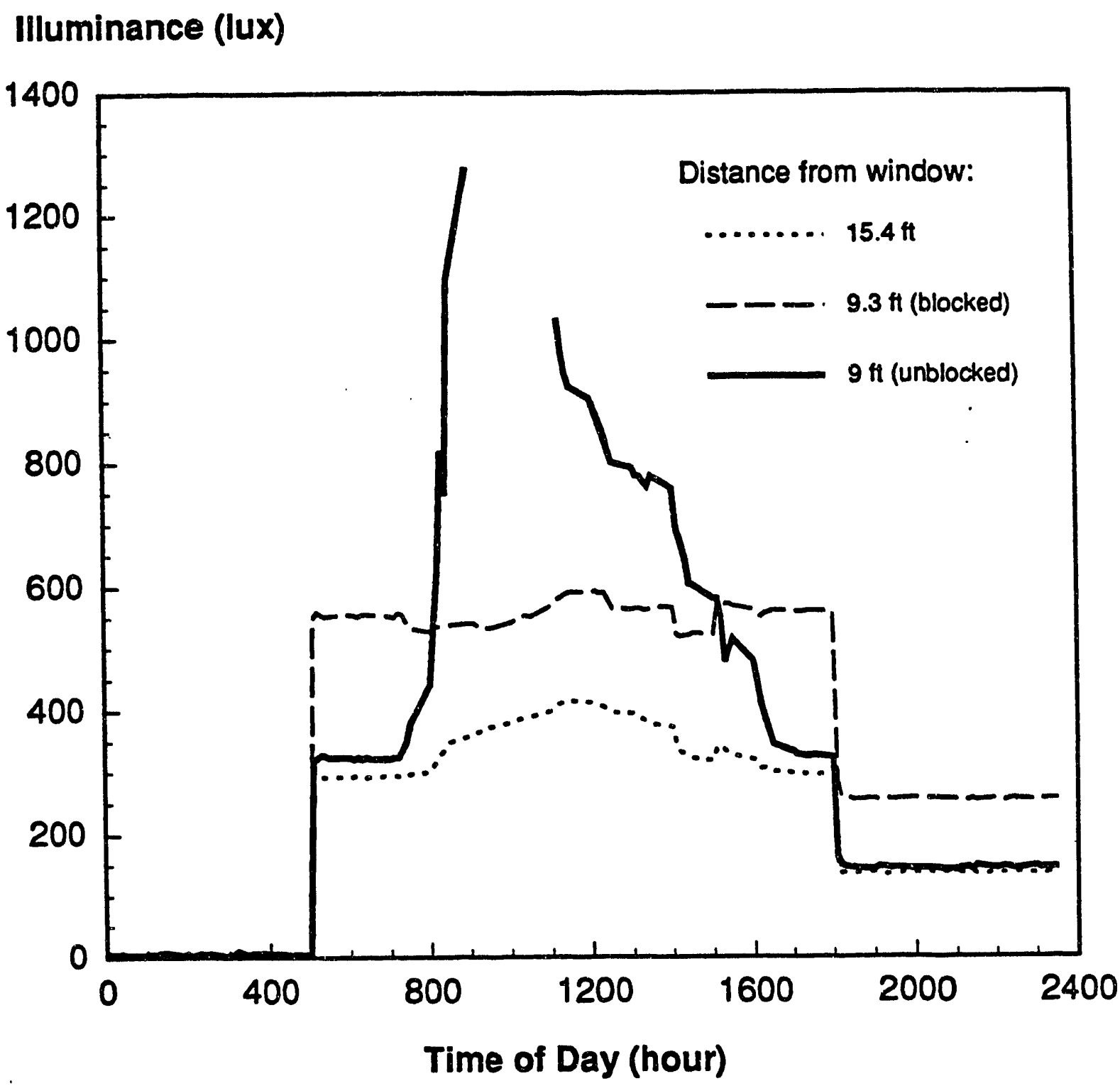

Figure 3-14. Workplane illuminance (33" above floor) at varying distances from south window for typical weekday (December 25, 1990) near the winter solstice. There are missing parts of the curve at $9 \mathrm{ft}$ from the window because the measuring instrumentation went off scale when direct sun fell on the photometer. 
mounted to the opposite side of the partition and is therefore blocked from seeing the window. Consequently, this photometer shows more moderate light levels that are fairly constant throughout the day at about $560 \mathrm{lux}$. The photometer at $15.4 \mathrm{ft}$ from the window also shows relatively constant light levels but at a lower level (approximately 300 lux). The low light levels here are caused by the partition, which blocks direct light from the closest luminaire. The dip in light level between 2 P.M. and 3 P.M. was a result of the load-shedding test. Despite the difficulties in the interpretation of the data, the reading from these photometers indicates that the control system is doing a satisfactory job of maintaining relatively constant light levels throughout the day, regardless of daylight level.

\section{TEMPERATURE MEASUREMENTS}

Lamp wall temperature, fixture compartment temperature, and plenum temperature for one day in January 1991 are shown in Figure 3-15. The lighting power for the zone (south daylit) that contains the thermocouple-instrumented fixture is superimposed on the same graph for reference. Over the day, the lamp wall temperature ranged from $29^{\circ} \mathrm{C}$ with the lamps off to $46-50^{\circ} \mathrm{C}$ with the lamps at nominal full output. As expected, the lamp temperature tracks fairly closely to changes in lighting power. The fixture compartment temperature is $6-12^{\circ} \mathrm{C}$ below the lamp wall temperature; when the lamps are off (between 3 A.M. and 5 A.M.), the values are the same $\left(29^{\circ} \mathrm{C}\right)$. The plenum temperature is the least sensitive to changes in lighting input power. Despite the relatively large changes in lighting power, the plenum temperature varies only between $26^{\circ} \mathrm{C}$ and $28^{\circ} \mathrm{C}$. Inspection of the temperature data for other occupied days during the winter, at least, indicate that the plenum temperatures are fairly constant from day to day. The relative constancy is of interest since standard fixture photometry is performed at an ambient temperature of $25^{\circ} \mathrm{C}$. Obtaining plenum temperatures only slightly higher than $25^{\circ} \mathrm{C}$ suggests that the inclusion of an application thermal factor to account for the difference in the test and field conditions in the design process may be unnecessary.

\section{LUMEN MAINTENANCE}

To demonstrate that the photocell control system adequately compensated for lumen depreciation effects over the long term, we have examined the light level measurements obtained at the workplane using the monitoring photometers in the north zone. To separate the confounding effects of daylight, we examined one day from each week of the year and selected the light level readings taken during the early morning hours before sunrise. Figure 3-16 shows these results for the photometers mounted at $4.5 \mathrm{ft}$ and $8.5 \mathrm{ft}$ from the window. The plot and linear regression for the photometer at $4.5 \mathrm{ft}$ from the window shows no significant correlation to time of year $\left(R^{2}=0.147\right)$ as would be expected for a system that maintains a constant light level independent of time of year. The linear regression fit to the data from the photometer at $8.5 \mathrm{ft}$ from the window does show a small increase in light, but since the coefficient of fit is only 0.476 , the increase is probably not significant. The increase averages to only about $3 \%$ per year compared to the $9.5 \%$ increase 
Temperature $\left({ }^{\circ} \mathrm{C}\right)$

Lighting Power (kW)

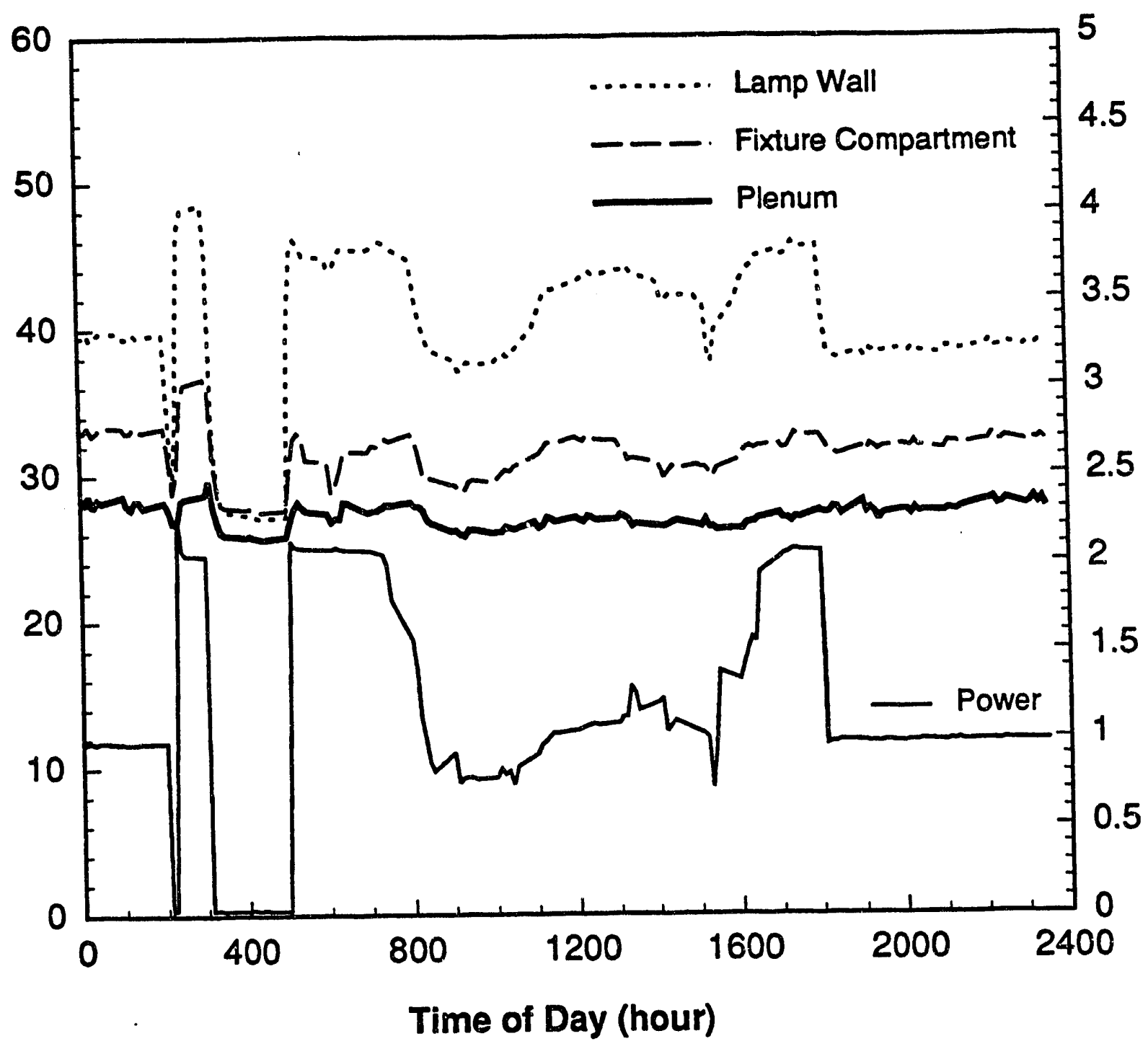

Figure 3-15. Lamp wall, fixture compartment, and plenum temperatures in the fixture instrumented with thermocouples on January 18, 1991 (clear day). The lighting power to the south daylit zone containing the instrumented fixture is also shown. 


\section{Workplane llluminance (lux)}

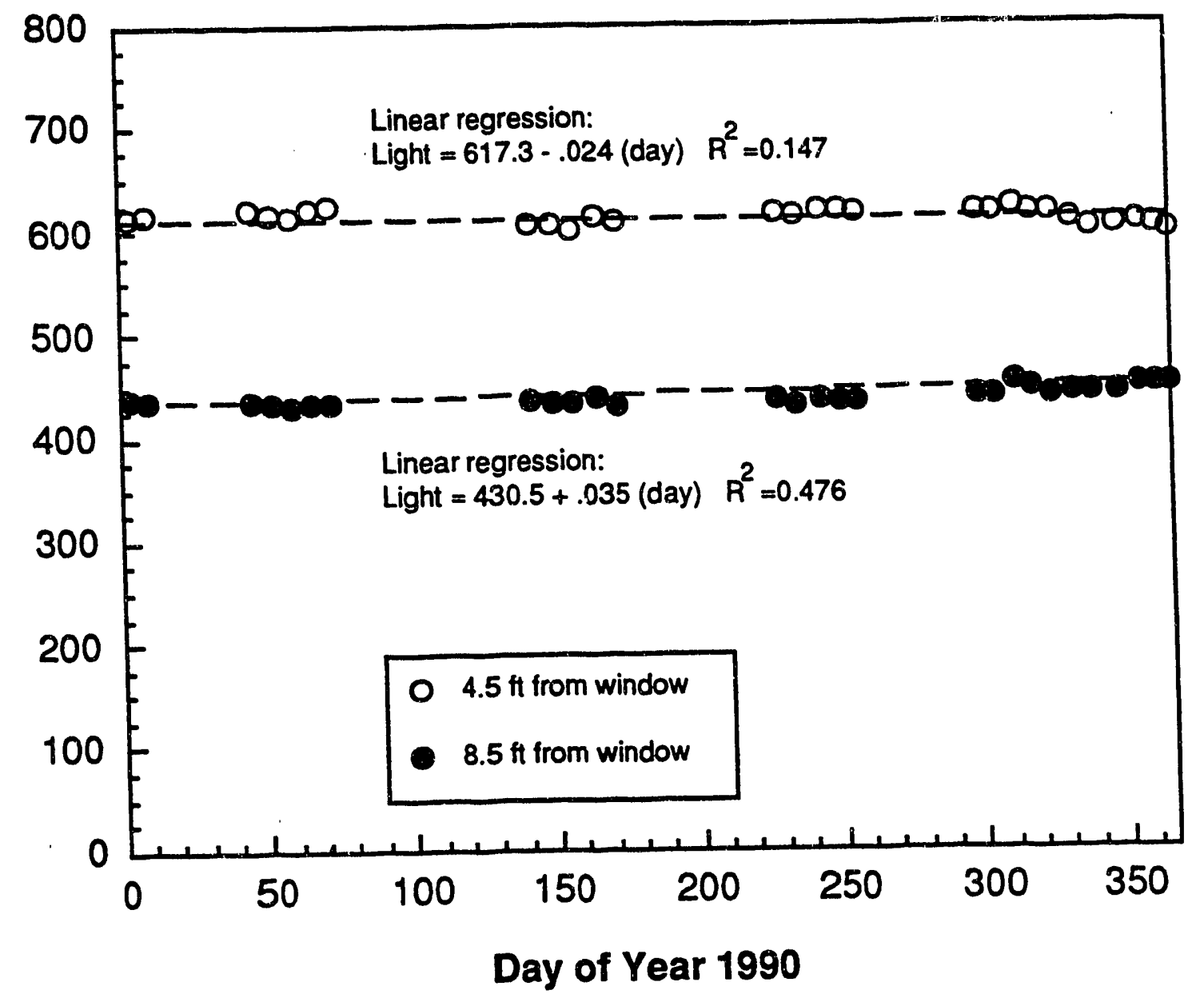

Figure 3-16. Workplane illuminance (42" above floor) due to electric light only at $4.5 \mathrm{ft}$ and $8.5 \mathrm{ft}$ from the north window for selected days in 1990. Data values occurring during early morning hours were selected to avoid daylight influence. Linear regressions for both photometers are presented along with regression coefficients. 
in core energy consumption over the year (see "Energy Savings, "Table 3-1). The small increase in light level is probaoly due to a slight miscalibration of the second string of lights in from the window wall.

\section{ENERGY SAVINGS}

Table 3-1 summarizes the average annual and seasonal weekday energy use for the three lighting control zones and the reference zone during 1990. The seasonal averages for spring, summer, and fall were computed by averaging the energy usage over a 1-month-long period centered around the equinoxes and the summer solstice (i.e., March 21, June 21, September 21). The winter usage is shown two ways: by averaging the lighting usage between January $\uparrow$ and January 31 and by averaging the usage between November 13 and December 13. Also shown is the variability of the average daily energy use expressed as the standard deviation of the individual daily energy use calculated over the number of days in the interval. The percent savings for each control case are calculated relative to the corrected daily use for the reference zone averaged over the year.

The daily lighting energy savings averaged over the year is $49-62 \%$. During the summer, the energy use during core hours in the north daylit zone is less than one-fourth of the usage in the reference zone. Interestingly, the usage in the north daylit zone is consistently less than that in the south daylit zone because the south zone occupants use drapes to reduce the direct sun penetration that would otherwise cause glare and excess heating in this zone.

By comparing the usage for November 13-December 13 to that of January $i$-January 31 , the effect of lumen maintenance is clearly discernible. Based on the core hour usage over this 11-month period, the energy usage is $9.5 \%$ higher in the north daylit zone at the end of this period than at the beginning. Similar results are seen in the south daylit zone. (The negative percent change for the south interior zones are not meaningful for this comparison since the control string over the aisleway in this zone was tuned to a low level in September.) There is a difference in usage because at the end of this period the lighting system has to supply more power (and thus consumes more total energy) to supply the same light level because of lumen depreciation (see Section 4).

The daylit zones generally saved more than the interior zone because of the lack of daylight in the inner zone. However, by reducing the light level over the aisleway in September, we reduced the energy use in the interior zone as well. This is most easily seen by comparing the usage in the spring and fall. While a small portion of this difference is due to lumen maintenance, most of the difference is attributable to the tuned lighting over the aisleway. The energy savings in the south interior zone tends to be less than that of the daylit zones because of the negligible daylight in this interior zone. 
Table 3-1

Average 1990 Weekday Lighting Energy Use

\begin{tabular}{|c|c|c|c|c|c|c|c|c|c|}
\hline \multirow[b]{2}{*}{ Perlod } & & \multicolumn{4}{|c|}{$\begin{array}{l}\text { Core Hours Only }-6 \text { a.m.-6 P.M. } \\
\text { (kWh/zone/12-hr) }\end{array}$} & \multicolumn{4}{|c|}{$\begin{array}{c}\text { All Day } \\
\text { (kWh/zone/day) }\end{array}$} \\
\hline & & $\begin{array}{l}\text { South } \\
\text { Dayllt }\end{array}$ & $\begin{array}{l}\text { South } \\
\text { Interlor }\end{array}$ & $\begin{array}{l}\text { North } \\
\text { Dayllt }\end{array}$ & Reference & $\begin{array}{l}\text { South } \\
\text { Dayllt }\end{array}$ & $\begin{array}{l}\text { South } \\
\text { Interior }\end{array}$ & $\begin{array}{l}\text { North } \\
\text { Daylit }\end{array}$ & Reference \\
\hline $\begin{array}{l}\text { Annual } \\
\text { Jan 1-Dec } 31 \\
259 \text { days }\end{array}$ & $\begin{array}{l}\text { Average } \\
\text { Std. Dev } \\
\% \text { Savedb }\end{array}$ & $\begin{array}{c}16.0 \\
3.0 \\
48.8 \%\end{array}$ & $\begin{array}{c}17.5 \\
3.0 \\
44.2 \%\end{array}$ & $\begin{array}{c}11.8 \\
3.9 \\
62.4 \%\end{array}$ & $\begin{array}{c}31.3^{a} \\
5.0\end{array}$ & $\begin{array}{c}27.9 \\
4.5 \\
51.1 \%\end{array}$ & $\begin{array}{c}28.0 \\
4.8 \\
50.8 \%\end{array}$ & $\begin{array}{c}21.4 \\
4.5 \\
62.4 \%\end{array}$ & $\begin{array}{c}57.0^{\circ} \\
9.0\end{array}$ \\
\hline $\begin{array}{l}\text { Spring } \\
\text { Mar 8-Apr } 5 \\
20 \text { days }\end{array}$ & $\begin{array}{l}\text { Average } \\
\text { Std. Dev } \\
\% \text { Saved }\end{array}$ & $\begin{array}{r}15.0 \\
3.6 \\
52 \%\end{array}$ & $\begin{array}{r}18.1 \\
4.3 \\
42 \%\end{array}$ & $\begin{array}{r}9.9 \\
2.5 \\
68 \%\end{array}$ & $\begin{array}{r}29.6 \\
7.0 \\
6 \%\end{array}$ & $\begin{array}{r}27.1 \\
6.6 \\
52 \%\end{array}$ & $\begin{array}{r}28.1 \\
6.7 \\
51 \%\end{array}$ & $\begin{array}{r}19.1 \\
4.5 \\
67 \%\end{array}$ & $\begin{array}{r}53.0 \\
11.9 \\
7 \%\end{array}$ \\
\hline $\begin{array}{l}\text { Summer } \\
\text { Jun } 8 \text {-Jul } 6 \\
20 \text { days }\end{array}$ & $\begin{array}{l}\text { Average } \\
\text { Std. Dev } \\
\% \text { Savedb }\end{array}$ & $\begin{array}{r}13.4 \\
3.1 \\
57 \%\end{array}$ & $\begin{array}{r}17.6 \\
4.3 \\
44 \%\end{array}$ & $\begin{array}{r}7.5 \\
1.7 \\
76 \%\end{array}$ & $\begin{array}{r}27.8 \\
8.8 \\
11 \%\end{array}$ & $\begin{array}{r}24.6 \\
4.8 \\
57 \%\end{array}$ & $\begin{array}{r}29.0 \\
6.0 \\
49 \%\end{array}$ & $\begin{array}{r}16.7 \\
3.0 \\
71 \%\end{array}$ & $\begin{array}{l}50.7 \\
13.7 \\
11 \%\end{array}$ \\
\hline $\begin{array}{l}\text { Fall } \\
\qquad \begin{array}{r}\text { Sep 8-Oct } 6 \\
17 \text { days }\end{array}\end{array}$ & $\begin{array}{l}\text { Average } \\
\text { Std. Dev } \\
\% \text { Saved }\end{array}$ & $\begin{array}{r}16.9 \\
4.7 \\
46 \%\end{array}$ & $\begin{array}{r}15.2 \\
4.3 \\
51 \%\end{array}$ & $\begin{array}{r}11.8 \\
3.5 \\
62 \%\end{array}$ & $\begin{array}{r}29.1 \\
7.5 \\
7 \%\end{array}$ & $\begin{array}{r}27.9 \\
6.8 \\
51 \%\end{array}$ & $\begin{array}{r}24.8 \\
6.2 \\
56 \%\end{array}$ & $\begin{array}{r}21.2 \\
5.2 \\
63 \%\end{array}$ & $\begin{array}{r}52.1 \\
11.8 \\
8 \%\end{array}$ \\
\hline $\begin{array}{l}\text { Winter } \\
\text { Jan } 1 \text {-Jan } 31 \\
23 \text { days }\end{array}$ & $\begin{array}{l}\text { Average } \\
\text { Std. Dev } \\
\% \text { Saved }\end{array}$ & $\begin{array}{r}17.1 \\
1.9 \\
45 \%\end{array}$ & $\begin{array}{r}18.7 \\
0.6 \\
40 \%\end{array}$ & $\begin{array}{r}15.5 \\
1.3 \\
51 \%\end{array}$ & $\begin{array}{r}29.9 \\
0.6 \\
5 \%\end{array}$ & $\begin{array}{r}28.4 \\
3.3 \\
50 \%\end{array}$ & $\begin{array}{r}28.6 \\
3.3 \\
50 \%\end{array}$ & $\begin{array}{r}23.7 \\
2.0 \\
58 \%\end{array}$ & $\begin{array}{r}53.0 \\
4.5 \\
7 \%\end{array}$ \\
\hline $\begin{array}{r}\text { Nov 13-Dec } 13 \\
23 \text { days }\end{array}$ & $\begin{array}{l}\text { Average } \\
\text { Std. Dev } \\
\% \text { Savedb } \\
\text { Winter \% Change }\end{array}$ & $\begin{array}{c}18.2 \\
3.3 \\
42 \% \\
6.0 \%\end{array}$ & $\begin{array}{c}14.7 \\
1.5 \\
53 \% \\
-27.4 \%\end{array}$ & $\begin{array}{c}17.1 \\
2.4 \\
45 \% \\
9.5 \%\end{array}$ & $\begin{array}{l}28.4 \\
6.2 \\
9 \% \\
-5.3 \%\end{array}$ & $\begin{array}{c}30.4 \\
4.4 \\
47 \% \\
6.3 \%\end{array}$ & $\begin{array}{c}24.2 \\
2.0 \\
57 \% \\
-18.1 \%\end{array}$ & $\begin{array}{l}27.5 \\
2.6 \\
52 \% \\
13.5 \%\end{array}$ & $\begin{array}{l}52.9 \\
10.4 \\
7 \% \\
-0.3 \%\end{array}$ \\
\hline
\end{tabular}

2Calculated energy use multiplied by $18 / 17$ to correct for the size difference of control and reference zones.

bavings relative to corrected annual average usage in reference zone. 
The energy savings measured on weekends are given in Table 3-2. The savings on weekends were quite signifix nt but show far greater variability than the savings on weekdays. The results are plotted in Figure 3-4.

Table 3-2

Average 1990 Weekend Lighting Energy Use (kWh/zone/day)

\begin{tabular}{|cccccc|}
\hline Period & & South Dayiit & South Interior & North Daylit & Reference \\
\hline \multirow{2}{*}{ Jan 1-Dec 31} & Average & 4.2 & 8.2 & 2.8 & $27.4^{\mathrm{a}}$ \\
104 days & Std. Dev. & 4.6 & 7.5 & 2.5 & $25.5^{\mathrm{a}}$ \\
& \% Saved & $84.8 \%$ & $70.2 \%$ & $89.8 \%$ & \\
\hline
\end{tabular}

alncludes 18/17 multiplier to correct for difference in size of control and reference zones.

bavings relative to corrected annual average usage in reference zone.

\section{PEAK DEMAND}

Since the energy savings and power reduction capabilities of controls are both of interest to utilities, we analyzed the data in terms of maximum demand between May and October (PG\&E's summer utility schedule). We examined the lighting power in all zones between the hours of 12:00 noon and 6:00 P.M., which corresponds to PG\&E's on-peak time for the summer schedule. Figure 3-17 shows the daily maximum lighting power reading for each day during this interval for all control zones and the reference zone. 


\section{Peak Demand (kW)}

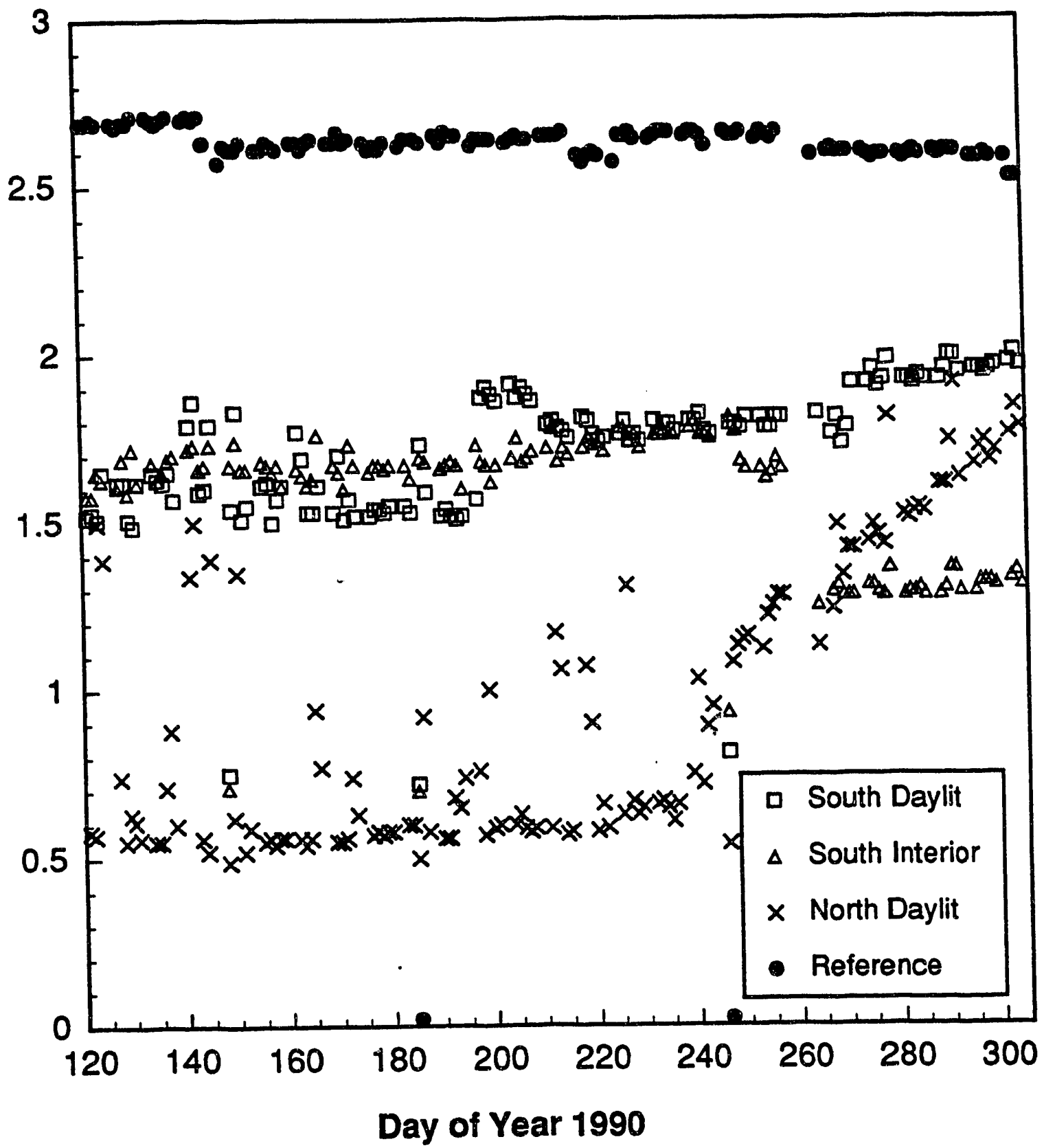

Figure 3-17. Maximum weekday lighting demand, May 1 to October 31, 1990, from 12 noon to 6 P.M. for north daylit zone, south daylit zone, south interior zone, and reference zone. 


\section{Section 4 \\ DISCUSSION}

\section{LUMEN MAINTENANCE}

One of the major objectives of this project was to document the long-term energy savings from the lumen maintenance control strategy and demonstrate appropriate photosensor design techniques required to implement this strategy effectively. Because the lumen depreciation effect that this control strategy responds to is, by nature, a long-term phenomenon (lamps lose only about $5 \%$ per year under typical use), the strategy can only be verified from long-term measurements such as the type presented here. In the plots shown earlier, the lighting usage at the end of 1990 was clearly higher than at the beginning of the year. Averaged between the south and north daylit zones, this increase in usage was approximately $8 \%$ over the year, which is consistent with the lumen depreciation rate expected in such an environment with these types of lamps. (Dirt depreciation also plays a role here. In a relatively clean environment such as office buildings, dirt depreciation of $5 \%$ per year is typical). Furthermore, we have shown that the light levels maintained by the electric light system remained generaliy constant over the year. (Note that this long-term constancy of light levels is in contrast to a conventional lighting system whose light output would drop over this time period but would consume constant power.) The combination of these two results (i.e., an increase in lighting power while light levels stay constant) serves to prove that lumen maintenance can be an effective strategy for reducing the lighting energy requirements in buildings while maintaining light levels.

It should be noted, however, that this strategy worked only because we set the lighting power input to $75 \%$ of maximum rather than full power when the system was first installed in anticipation of the expected amount of lumen depreciation. One would expect that the slow increase in lighting consumption documented here will continue until, after about 3 years, the lighting power would approach maximum (i.e., 100\%). At this point, the lighting system will have to be group relamped and the fixtures cleaned if the lumen maintenance savings pattern is to be repeated over the next maintenance cycle. If, on the other hand, the lamps are spot replaced as they fail, then the savings accrued with this strategy will be reduced.

\section{DAYLIGHTING}

Certainly one of the more surprising results of the summer lighting energy usage pattern was the significantly larger savings found in the north zone than in the south zone. Because the occupants in the south zone close the drapes during most working hours to reduce the glare and thermal discomfort caused by the direct sun, they solve the glare problem at the expense of energy savings. The drapes in this building are of a heavy, coarse, loose-weave construction that reduces the incoming light by nearly a factor of ten. 


\section{TUNING}

Electric lighting usage was reduced by $40 \%$ by tuning the entire row of lights over the aisle way to a low level. Extrapolating this tuning savings to other building types is hazardous. Every floor plan design is unique and must be considered individually. However, it should be noted that the type of tuning practiced here is only the simplest form of this strategy. The ballasts used in this demonstration project can be individually adjusted with a potentiometer mounted directly to the ballast.

\section{PHOTOSENSOR CONTROL}

The two-part photosensor system worked remarkably well in maintaining a constant workplane illuminance. To our knowledge, this is the first demonstration of a closed loop photosensor-controlled system that correctly compensates for both changes in daylight and lumen depreciation in the electric lighting system. This was verified both in the open office area in the north zone and in the partitioned office area in the south. The use of a control photosensor, whose response can be adjusted so that the relationship between photocell output and workplane illuminance is the same for daylight and electric light, is one of the outstanding features of this system. Without this photosensor, system response can be optimized for either daylighting (by using open loop control as at Lockheed [Benton 1989] or with closed loop proportional control [Rubinstein et al. 1989]) or lumen maintenance, but not both simultaneously. The natural integration of these two photo-linked strategies is of great signiticance since the overlapping hardware requirements (i.e., dimmability with photosensor control) and the sizeable energy savings are necessary to justify the premium cost of dimming hardware.

\section{OVERRIDE USE PATTERNS}

We found that the overrides were used primarily to raise the light level from the default reduced level to the nominal full level during very early morning hours. It is also signiticant that all three zones, not just one, were often overridden, which could be due to the master override sequence being used instead of the individual zone sequence (perhaps out of occupant ignorance). It may also be that the occupant intentionally overrode the lights in all three zones because work needed to be done in more than one zone. Regardless, one can deduce from the switching pattern that at least a few individuals work in parts of this site in the very early morning hours and that they leave between 2 A.M. and 3 A.M. Since the reduced cleaning crew level is rarely overridden until 2 A.M. (when the scheduling system would have the lights dimmed off), one can speculate that some individuals may find the reduced level adequate to work by at night and that they use the overrides just when the lights are switched off. (The occupants had no way of obtaining the reduced level; their overrides would only restore to full lighting.) 


\section{COST-EFFECTIVENESS}

No energy conservation measure can be successful unless one can demonstrate cost-effectiveness. Since the system examined in this project is an advanced commercial prototype without a set price, we use the calculated energy savings to estimate what the cost of the ballast and ancillary controls should be (i.e., target costs) to achieve an acceptable payback for a commercial building. We derive target costs for the retrofit in this building and a newly constructed building that is in compliance with Title 24 . We assume that a $50 \%$ energy savings can be achieved in both rases.

Since the lighting system at this demonstration site used $2.5 \mathrm{~W} / \mathrm{ft}^{2}$ for lighting for $7,000 \mathrm{hr} / \mathrm{yr}$ before the retrofit, lighting cost $\$ 1.40 / \mathrm{t}^{2} / \mathrm{yr}$ at an energy cost of $\$ 0.08 / \mathrm{kWh}$. This study indicates that we can (conservatively) save half of this cost using a lighting control system: $\$ 0.70 / \mathrm{tt}^{2} / \mathrm{yr}$. If we assume that the first cost of retrofitting the control system must be recovered in two years, then the total installed first cost must not exceed $2 \times \$ 0.70 / \mathrm{ft}^{2}$, or $\$ 90.00 / f x$ ture since each fixture lights $64 \mathrm{ft}^{2}$. By allowing $\$ 25.00 / f i x t u r e$ for the labor cost to retrofit each fixture, install the controls, and calibrate the system, and an additional $\$ 10.00 / f i x t u r e$ for the controls cost (photocells, EMS linkage, override switches, and wiring) we get a ballast target cost of $\$ 54.60 /$ ballast. We believe that this is well within the range of market profitability. Note also that this calculation does not consider any applicable utility rebate, which would significantly improve the cost-effectiveness to the building owner. (PG\&E currently offers a $\$ 10.00 /$ ballast rebate. Some utilities in the northeast offer rebates over $\$ 20.00 /$ ballast.) If we assume that the building would have been reballasted anyway, then the $\$ 54.60$ /ballast figure just derived can be considered a cost premium. Under this assumption, the target cost becomes approximately $\$ 75.00$ /ballast. (The 3-lamp electronic ballast replaces two energy-efficient core-coil ballasts that cost $\$ 10.00$ each).

For new construction, these figures must be adjusted because the installed lighting power density is lower in a Title 24 office building than in most existing buildings, and the hours of operation would probably also be less because of Title 24's stringent local switching requirements. In the new construction case, the building lighting energy costs without controls would be expected to be about only $\$ 0.56 / \mathrm{t}^{2} / \mathrm{yr}\left(2.0 \mathrm{~W} / \mathrm{ft}^{2} \times\right.$ $3,500 \mathrm{hrs} / \mathrm{yr} \times \$ 0.08 / \mathrm{kWh}){ }^{1}$ Again assuming that the control system can save $50 \%$ of the lighting energy costs gives us a total installed first cost of $\$ 53.75 /$ fixture if the system is to pay back in 3 years. For new construction, we may assume that the labor to install the controls is only $\$ 5.00 /$ fixture to reflect the low costs of installing a control system when it is incorporated into the design plans from the start. Allowing, as before, an additional cost of $\$ 10.00 / f i x t u r e$ for the controls cost results in a target cost premium of $\$ 38.75 /$ ballast. Note that this is the premium cost, i.e., the "adder" that the end user would be willing to pay above the cost

\footnotetext{
'Although a Title 24 office building may only use $1.5 \mathrm{~W} / \mathrm{ft}^{2}$ ior lighting, we have used $2 \mathrm{~W} / \mathrm{t}^{2}$ to account tor the aliowed power adjustment credit for controls. We have used $35 \%$ for this credit, which is intended to be a weighted average value over the building.
} 
of an energy-efficient core-coil ballast (which we assume costs $\$ 10.00$ each as above). This results in an end-user target cost of $\$ 58.75 /$ ballast. Dimming electronic ballasts can be profitably marketed at this price. However, the target cost would be lower if we had required a 2-year payback instead of the 3 years assumed above. Also, the actual cost to the end user would be only $\$ 48.75 /$ ballast if one takes into account the $\$ 10.00$ PG\&E rebate.

The above economic analyses are believed to be conservative since we have not accounted for the additional cost savings from the reduced cooling load.

\section{RELIABILITY}

\section{Ballasts}

Throughout the course of this 2-year project (since installation of the electronic ballasts in May 1989), approximately 10 of the electronic ballasts either failed or exhibited sufficiently anomalous behavior so that they had to be replaced. This failure rate, although high for a commercial ballast, is remarkably low considering that they were hand-built prototypes. Most of the failures appear to be attributable to quality assurance errors in sorting out defective devices (particularly diodes in the diode bridge) rather than to the design. We are therefore reasonably certain that these problems are resolvable in the manufacturing process.

\section{Lamps}

At the start of this demonstration, there was a problem with shortened lamp life due to low-cathode heating voltage at full dim (Rubinstein and Verderber 1990). Once the ballasts were modified to provide full heating power at all dimming levels, the shortened lamp life problem was resolved. Since the system was relamped in September 1989, only 3 lamps (out of 162) have failed. Funthermore, there has been almost no sign of lamp blackening on any of the lamps.

\section{Controls}

Except for a faulty switch on the string 5 controller board, the controls have functioned satisfactorily. Our results suggest that the two-part photocelis are an elegant and effective way to detect and control light levels so that both daylighting and lumen maintenance can be simultaneously implemented with the same hardware. To our knowledge this is the first demonstration of such an integrated system for which long-term performance has been measured.

The controller used in this system has a very fast response time, with a time constant of only 2 seconds. That is, if there is a sudden change in the light level sensed by the ceiling photosensors, the system dims 
in just a few seconds. "Common knowledge" has it that the response of daylight-linked lighting systems should be slow (i.e., on the order of 30 seconds). However, despite our initial concerns about the speed of the system response, our experience at this site indicates that a fast-responding system is not obtrusive to the occupants. This has some significance for the load-shedding strategy since a heavily damped system might not respond quickly enough to avoid the incurrence of a peak demand penalty. (The author knows of one European dimming system that has a time constant of several minutes.) 


\section{Section 5}

\section{CONCLUSIONS AND RECOMMENDATIONS}

This demonstration has shown that a properly designed and calibrated photoelectrically controlled dimming system can effect significant reductions in energy use by exploiting several control strategies in concert. The data collected during the summer indicate that energy savings of $75 \%$ relative to the original lighting usage is achievable. The energy savings were found to be both significant and consistent, atthough the effect of time of year was discernible in the daylit zones. Equally important, the measured demand reduction during core operating hours-up to $70 \%$ during the summer months-argues that lighting control be seriously considered for moderating peak demand.

A novel two-part control photosensor was shown to be effective in providing appropriate control, allowing daylighting and lumen maintenance strategies to be implemented simultaneously with the same hardware. With this photocontrol system, design light levels were maintained at the workplane regardless of the daylight contribution or the age of the lighting system. Although the photocontrol system operated quite satisfactorily, we identified a need to simplify the calibration and commissioning process to assure that the savings documented here can be achieved routinely.

The energy savings documented in this demonstration were accomplished without compromising the quality of the lighting. A simple survey of occupant response indicated that the majority of respondents were satisfied with the light levels provided.

We cannot stress enough the importance of the measured energy and demand reductions. Buildings are the most significant users of electrical energy in the nation, and lighting is the major contributor to total electrical loads in buildings. It would not seem to be too extreme a viewpoint to state that the use of appropriate lichting controls is probably the most cost-effective method to significantly reduce electrical energy use and peak demand in buildings.

This project has also revealed that the application of dynamic lighting systems is more complicated than "static" lighting because one must consider factors, such as window orientation and occupant behavior, that are largely ignored in designing conventional lighting. In addition, the successful commissioning of a photoelectrically controlled lighting system requires expertise that is not readily available. Appropriate design and application of sophisticated dynamic lighting systems will not be widespread until designers and specifiers become more experienced in applying dynamic lighting design concepts. Finally, the cost of

$00819121 / 918443 /$ ppu276 
dimming electronic ballasts and associated controls must come down in price before lighting controls are widely applied.

For lumen maintenance to be a successful, long-term energy saving strategy in buildings, a commitment by the facilities management to group relamping and system maintenance is necessary. But in most circumstances, group relamping is cost effective even without the lumen maintenance control strategy. If the lighting is initially dimmed and then set to automatically compensate for lumen depreciation as was done here, group relamping becomes even more cost effective.

It would be of considerable interest to investigate whether an alternative shading system would block the direct sun penetration while blocking less of the useful light from the sky. A louvered blind system, possibly with an automatic control, would be a good candidate for this application.

In buildings with a uniform ceiling luminaire grid, tuning has great potential because individual luminaires are often poorly located for task surfaces, so poorly located fixtures can be tuned to low level without any deterioration in worker productivity. In fact, if a ceiling fixture causes veiling reflections either on the horizontal task or off a computer screen, tuning the offending fixture to low level will improve occupant comfort and productivity. This control was not explored in this project but it should not be ignored in future installations.

The calibration procedure for the daylighting control clearly needs to be simplified. Instead of moving the photosensor stalk up and down to obtain the correct photosensor response for daylight and electric light, it would be preferable to fix the photosensor in one location in selected fixtures shipped to the job site and to balance the signals from the two sensors electrically. Furthermore, the adjustment controls should be placed in a location where they can be easily reached from the controlled space.

Addressing these issues is a formidable task beyond the resources of any one institution. But the utilities can play a more active role in promulgating the use of energy-efficient lighting controls by assisting in certain targeted areas:

- Commence a research effort focused at developing simplified methods for zoning and installing lighting controls systems in new buildings.

- Continue and expand support of improved computer tools for analyzing the lighting usage patterns in existing buildings and identifying those areas where controls can be most cost effectively applied. 
- Continue and expand utility demand-side management programs that encourage owners to invest in controls by reducing the initial added cost.

- Assist in the development of educational programs for building management personnel to help these individuals understand the importance of a properly operated and calibrated control system. 


\section{Section 6}

\section{REFERENCES}

Benton, C. 1989. The Lockheed Building 157 Monitoring Project Phase II: The Lighting Control System. Report 008.1-89.7. Prepared for the Department of Research and Development. San Ramon: Pacific Gas and Electric Company.

Department of Energy. May 1989. Analysis and Technology Transfer Annual Report 1988. Buildings and Community Systems. Washington, D.C.

Jaekel, R. R., and Rea, M. January 1983. A Case Study of a Daylight-Linked Dimming System for Fluorescent Lamps. National Research Council Building Research Note No. 194. Ottawa, Canada.

Levy, A. May/June 1980. Lighting Controls, Patterns of Lighting Consumption, and Energy Conservation. IEEE Transactions on Industry Applications, Vol. 1A-16, no. 3.

Rubinstein, F., and M. Karayel. 1984. "The Measured Energy Savings From Two Lighting Control Strategies." IEEE Transactions on Industry Applications IA-20, no. 5: 1189-97.

Rubinstein, F. and R. Verderber. 1990. Automatic Lighting Controls Demonstration. Report 008.1-89.24. Prepared for the Department of Research and Development. San Ramon: Pacific Gas and Electric Company.

Rubinstein, F., G. Ward, and R. Verderber. Winter 1989. "Improving the Performance of Photo-Electrically Controlled Lighting Systems." Journal of the Illuminating Engineering Society 18, no. 1. 
Appendix A GLOSSARY

-

00819121/918443/ppu276 


\section{GLOSSARY}

Ballast:

Ballast factor:

Ccritrol group (also control string):

Control zone:

Daylight:

Daylight control (also daylighting):

Dimmer:

Efficacy:

Electronic ballast:

Footcandle (fc):

IESNA:

Illuminance:

Lamp:

Lighting control:

Load shedding:

Lumen:
A device used with a fluorescent lamp to provide the correct starting voltage and maintain the appropriate current conditions for operating the lamp.

The lumen output of a lamp operated by a commercial ballast divided by the lumen output of the same lamp operated on a reference circuit.

A group of light fixtures controlled together to provide the same illumination level.

All fixtures on one lighting branch circuit.

Light from the sky and sun used to provide illumination for the performance of visual tasks.

An energy-saving lighting control strategy in which a photocell is used with a dimming system to provide a fixed light level at the workplane by increasing the amount of electriclight with decreasing daylight levels and decreasing the amount of electric light with increasing daylight.

A control device for varying the light output from lamps.

The ratio of light output from a lamp to the electrical input power, expressed in lumens per watt (LW).

A solid-state ballast that converts 60 cycle electric power to high frequency $(20-60 \mathrm{kHz})$ power to drive a fluorescent lamp.

A unit of illuminance; the illumination on a one-foot-square surface on which there is a uniformly distributed flux of one lumen.

Illuminating Engineering Society of North America.

Lighting level, expressed in footcandles (English unit) or lux (metric unit).

Engineering term for light source, commonly referred to as a bulb or tube.

General term referring to the devices and techniques necessary to provide the right amount of light where and when needed.

A lighting control strategy for selectively reducing the output of lighting fixtures on a temporary basis as a means to reduce peak demand charges.

Basic unit of light flux. 
Lumen maintenance:

Luminaire:

Lux:

Override:

Photocell:

Photometer:

Photosensor:

Scheduling:

Troffer:

Tuning:

Workplane:
An energy-saving lighting control strategy in which a photocell is used with a dimming system to provide a fixed light level over the maintenance cycle.

A complete lighting unit consisting of a lamp (or lamps), together with a housing, the optical components to distribute the light from the lamps, and the electrical components (ballasts, starters, etc.) necessary to operate the lamps.

A unit of illuminance; the illumination on a one-meter-square surface on which there is a uniformly distributed flux of one lumen.

A switch that can be used by occupants to obtain lighting when required outside of normal operating hours. May be activated using a touchtone telephone.

A light-sensitive device for measuring a quantity of light. The Braydon Corporation used silicon photodiodes for this demonstration.

An instrument for measuring lighting quantities such as illuminance and luminance.

A sensor comprised of photocell(s) to control the illuminance of the lighting system.

An energy-saving lighting control strategy for dimming or otherwise reducing light levels during hours when a building space is unoccupied or occupied by individuals with less stringent lighting requirements.

A recess-mounted lighting fixture.

An energy-saving lighting control strategy in which the light output of an individual fixture or group of fixtures is adjusted to provide the correct amount of light for a local task.

The plane at which work is performed and at which illumination is specified and measured. Usually taken to be 30" above the floor. 

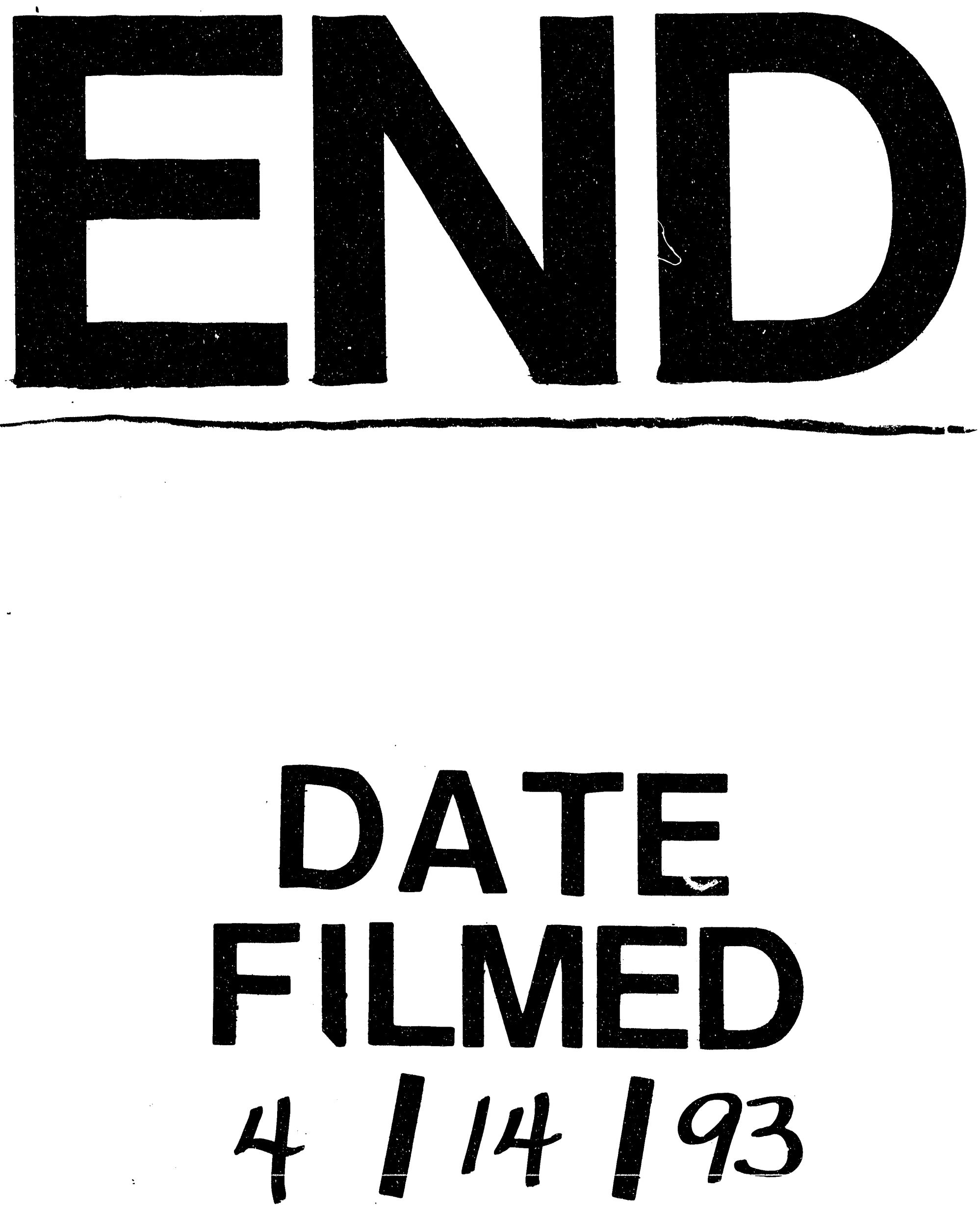

E 
